NBER WORKING PAPER SERIES

ACCOUNTING FOR THE RISE IN COLLEGE TUITION

\author{
Grey Gordon \\ Aaron Hedlund \\ Working Paper 21967 \\ http://www.nber.org/papers/w21967 \\ NATIONAL BUREAU OF ECONOMIC RESEARCH \\ 1050 Massachusetts Avenue \\ Cambridge, MA 02138 \\ February 2016
}

The views expressed herein are those of the authors and do not necessarily reflect the views of the National Bureau of Economic Research. This research was supported in part by Lilly Endowment, Inc., through its support for the Indiana University Pervasive Technology Institute, and in part by the Indiana METACyt Initiative. The Indiana METACyt Initiative at IU is also supported in part by Lilly Endowment, Inc.

NBER working papers are circulated for discussion and comment purposes. They have not been peerreviewed or been subject to the review by the NBER Board of Directors that accompanies official NBER publications.

(C) 2016 by Grey Gordon and Aaron Hedlund. All rights reserved. Short sections of text, not to exceed two paragraphs, may be quoted without explicit permission provided that full credit, including $\odot$ notice, is given to the source. 
Accounting for the Rise in College Tuition

Grey Gordon and Aaron Hedlund

NBER Working Paper No. 21967

February 2016

JEL No. D40,D58,E21,G11

\begin{abstract}
$\underline{\text { ABSTRACT }}$
We develop a quantitative model of higher education to test explanations for the steep rise in college tuition between 1987 and 2010. The framework extends the quality-maximizing college paradigm of Epple, Romano, Sarpca, and Sieg (2013) and embeds it in an incomplete markets, life-cycle environment. We measure how much changes in underlying costs, reforms to the Federal Student Loan Program (FSLP), and changes in the college earnings premium have caused tuition to increase. All these changes combined generate a 106\% rise in net tuition between 1987 and 2010, which more than accounts for the $78 \%$ increase seen in the data. Changes in the FSLP alone generate a $102 \%$ tuition increase, and changes in the college premium generate a $24 \%$ increase. Our findings cast doubt on Baumol's cost disease as a driver of higher tuition.
\end{abstract}

Grey Gordon

Indiana University

Wylie Hall

$100 \mathrm{~S}$ Woodlawn Ave

Bloomington, IN 47405-7104

greygordon@gmail.com

Aaron Hedlund

University of Missouri

118 Professional Building

Columbia, MO 65211

hedlunda@missouri.edu 


\title{
Accounting for the Rise in College Tuition*
}

\author{
Grey Gordon ${ }^{\dagger} \quad$ Aaron Hedlund ${ }^{\ddagger}$
}

September 28, 2015

\begin{abstract}
We develop a quantitative model of higher education to test explanations for the steep rise in college tuition between 1987 and 2010. The framework extends the qualitymaximizing college paradigm of Epple, Romano, Sarpca, and Sieg (2013) and embeds it in an incomplete markets, life-cycle environment. We measure how much changes in underlying costs, reforms to the Federal Student Loan Program (FSLP), and changes in the college earnings premium have caused tuition to increase. All these changes combined generate a $106 \%$ rise in net tuition between 1987 and 2010, which more than accounts for the $78 \%$ increase seen in the data. Changes in the FSLP alone generate a $102 \%$ tuition increase, and changes in the college premium generate a $24 \%$ increase. Our findings cast doubt on Baumol's cost disease as a driver of higher tuition.
\end{abstract}

Keywords: Higher Education, College Costs, Tuition, Student Loans JEL Classification Numbers: E21, G11, D40, D58

\section{Introduction}

Over the past thirty years, the perceived necessity of having a college degree and a growing college earnings premium have led to record enrollments and greater degree attainment in higher education. However, a dramatic escalation in tuition looms over the heads of many parents of prospective students and serves as a stark reminder to graduates saddled with

${ }^{*}$ We thank Kartik Athreya, Sue Dynarski, Gerhard Glomm, Bulent Guler, Kyle Herkenhoff, Jonathan Hershaff, Felicia Ionescu, John Jones, Michael Kaganovich, Oksana Leukhina, Lance Lochner, Amanda Michaud, Brent Hickman, Chris Otrok, Urvi Neelakantan, Fang Yang, Eric Young, and participants at Midwest Macro 2014 and the brown bags at Indiana University and the University of Missouri. All errors are our own.

†'Indiana University, greygordon@gmail.com

${ }^{\ddagger}$ University of Missouri, hedlunda@missouri.edu 
large student loans. From 1987 to 2010, sticker price tuition and fees ballooned from $\$ 6,600$ to $\$ 14,500$ in 2010 dollars. After subtracting institutional aid, net tuition and fees still grew by $78 \%$, from $\$ 5,790$ to $\$ 10,290$. To provide perspective, had net tuition risen at the rate of much maligned healthcare costs, tuition would have only reached about $\$ 8,700$ in $2010 .^{1}$

In this paper, we seek to account for the college tuition increase by quantitatively evaluating existing explanations using a structural model of higher education and the macroeconomy. We divide our hypotheses about driving forces into supply-side changes (Baumol's cost disease and exogenous changes to non-tuition revenue), demand-side changes (notably, expansions in grant aid and loans), and macroeconomic forces (namely, skill-biased technical change resulting in a higher college earnings premium). Our quantitative model shows that the combined effect of these changes more than accounts for the tuition increase and provides key insights about the role of individual factors as well as their complementary effects.

Existing hypotheses about increasing college tuition largely fall into two camps: those that emphasize the unique virtues and pathologies of higher education and those that place rising higher education costs into a broader narrative of increasing prices in many service industries. Advocates of the latter approach look to cost disease and skill-biased technical progress as drivers of higher costs in service industries that employ highly skilled labor. Cost disease, which dates back to seminal papers by Baumol and Bowen (1966) and Baumol (1967), posits that economy-wide productivity growth pushes up wages and creates cost pressures on service industries that do not share in the productivity growth. To cope, these industries increase their relative price and pass the higher costs onto consumers.

By contrast, theories emphasizing the uniqueness of higher education take several forms. Falling within our notion of supply-side shocks, state and local funding for higher education fell from \$8,200 per full-time-equivalent (FTE) student in 1987 to $\$ 7,300$ in 2010, all while underlying costs and expenditures were rising. Several studies, including a notable study commissioned by Congress in the 1998 re-authorization of the Higher Education Act, attribute a sizable fraction of the increase in public university tuition to these state funding cuts. We take a somewhat broader view in this paper by looking at how exogenous changes to all sources of non-tuition revenue impact the path of tuition.

On the demand side, several expansions in financial aid have occurred over the past several decades. During our period of analysis, annual and aggregate subsidized Stafford loan limits were increased in 1987 and five years later in 1992. The Higher Education Amendments of 1992 also established a program of supplementary unsubsidized Stafford loans and increased the annual PLUS loan limit to the cost of attendance minus aid, thereby eliminating aggregate PLUS loan limits. Interest rates on student loans also fell considerably during

\footnotetext{
${ }^{1}$ Calculations used the health care personal consumption expenditures price index.
} 
the 2000s. In a famous 1987 New York Times Op-Ed titled "Our Greedy Colleges", then secretary of education William Bennett asserted that "increases in financial aid in recent years have enabled colleges and universities blithely to raise their tuitions" (Bennett, 1987). We evaluate this claim through the lens of our model, and we also cast light on the tuition impact of the $53 \%$ rise in non-tuition costs (such as those arising from the greater provision of student amenities), which has the effect of increasing subsidized loan eligibility.

Lastly, we quantify the impact of macroeconomic forces - specifically, rising labor market returns to college - on tuition changes. Autor, Katz, and Kearney (2008) find that, from the mid-1980s to 2005, the overall earnings premium to having a college degree increased from $58 \%$ to over $93 \%$. Ceteris paribus, such an increase in the return to college has assuredly driven up demand for a college degree. We use our model to quantify how much this increase in demand translates to higher tuition and how much it contributes to higher enrollments.

Our quantitative findings can be summarized as follows:

1. The combined effect of the aforementioned shocks generates a $106 \%$ increase in equilibrium tuition. This result compares to a $78 \%$ increase in the data.

2. The rise in the college earnings premium alone causes tuition to increase by $24 \%$. With all other shocks present except the college premium hike, tuition increases by $87 \%$.

3. The demand-side shocks by themselves cause tuition to jump by $102 \%$. With all other changes except the demand-side shocks, tuition only increases by $16 \%$.

4. The supply-side shocks by themselves cause tuition to decline by $6 \%$. With all other changes except the supply-side shocks, tuition increases by $122 \%$.

The model we construct to arrive at these conclusions integrates the framework of imperfectly competitive, price discriminating, quality maximizing colleges by Epple, Romano, and Sieg (2006) and Epple et al. (2013) into a life-cycle, heterogeneous agent, incomplete markets environment with student loan default. In this paper, we focus on the case of a representative, non-profit college that faces a balanced budget constraint. We defer issues surrounding college endowment accumulation and the strategic interaction between heterogeneous colleges to future work. In the model, revenues include endogenous tuition and exogenous non-tuition revenue (e.g. endowment income and state funding). Expenditures consist of endogenous investment and non-quality-enhancing custodial costs. To prevent the college from extracting the entire consumer surplus from students, we follow Epple et al. (2013) by adding unobservable preference shocks to the utility of attending college, as seen commonly in many discrete choice models. On the household side, we include several poten- 
tially important features: heterogeneity in ability and parental income dimensions, college financing decisions, college drop-out risk, and student loan repayment decisions.

Our assumption that colleges maximize quality - in line with what Clotfelter (1996) calls the "pursuit of excellence" - implicitly incorporates another prominent hypothesis for rising tuition, namely, Bowen (1980)'s "Revenue Theory of Costs." Ehrenberg (2002) states it best:

The objective of selective academic institutions is to be the best they can in every aspect of their activities. They aggressively seek out all possible resources and put them to use funding things they think will make them better. To look better than their competitors, the institutions wind up in an arms race of spending...

To make matters concrete, quality in our setting depends on investment per student and the average ability of the student body. As a result, students act both as customers and as inputs to the production of quality via peer effects, as described by Winston (1999). This unique feature of higher education gives colleges an additional motive to engage in price discrimination beyond the usual monetary rent extraction-namely, to attract high ability students by offering generous institutional aid.

To discipline the model, we use a combination of calibration and estimation. Rather than ex-ante assume cost disease or a particular production structure (e.g. number of faculty, administrators, etc. needed to run a college), we directly estimate the reduced-form custodial cost function and track its changes over the period 1987 - 2010. Similarly, we compute average non-tuition revenue per full-time equivalent (FTE) student using Delta Cost Project data and feed it into the model. On the household side, we use earnings premium estimates by Autor et al. (2008) and construct time-series for Federal Student Loan Program variables.

As mentioned previously, we find that the combined effects of the supply-side changes, demand-side changes, and increases in the college earnings premium can fully account for the mean net tuition increase. Looking at individual factors, we find that expansions in borrowing limits drive $40 \%$ of the tuition jump and represent the single most important factor. ${ }^{2}$ To grasp the magnitude of the change in borrowing capacity, first note that real aggregate borrowing limits increased by $56 \%$ between 1987 and 2010, from $\$ 26,200$ to $\$ 40,800$ in 2010 dollars. $^{3}$ Second, the re-authorization of the Higher Education Act in 1992 introduced a major change along the extensive margin by establishing an unsubsidized loan program. We also find that increased grant aid contributes $17 \%$ to the rise in tuition, which mirrors the $18 \%$ impact of the higher college earnings premium. Our model also suggests that financial aid increases

\footnotetext{
${ }^{2}$ For this calculation, we take one minus the tuition increase without the borrowing limit expansion relative to the increase with the expansion, i.e. $1-(\$ 9,949-\$ 6,100) /(\$ 12,559-\$ 6,100)$. Adding the percentage contribution from each exogenous driving force need not yield $100 \%$ because of interaction effects.

${ }^{3}$ We use the limits in place from 1981 to 1986 as our figure for 1987.
} 
tuition at the bottom of the tuition distribution more so than it does at the top. These results give credence to the Bennett (1987) hypothesis.

Lastly, our results cast doubt on the role of cost disease as a driver of higher tuition. Although our estimated cost function shifts upward from 1987 to 2010, this isolated effect reduces average tuition (a contribution of -17\%). Intuitively, colleges face a trade-off between raising tuition and retaining high ability students when they experience a balance sheet deterioration. If they increase tuition, fewer high ability students may enroll, which drives down quality. Alternatively, a decision to not raise tuition forces colleges to cut back on quality-enhancing investment expenditures. We find that colleges take this latter route to the tune of almost $\$ 1,900$ in cuts per student as a response to higher custodial costs. This result comports with the behavior we observe among many public universities across the country of replacing tenured faculty with less expensive non-tenure-track positions. Additionally, changes in non-tuition revenue have almost no impact on tuition (a contribution of $-4 \%$ ).

We do not claim that Baumol's cost disease or changes in government aid have no importance for tuition increases. Rather, we suspect that these factors affect some colleges more than others. For instance, if private research universities experience cost disease, they may increase their tuition. However, higher tuition may induce substitution of students into lower cost universities. Given the absence of competition and college heterogeneity in our model, our estimation implicitly incorporates substitution of households across college types and any corresponding composition effects.

\subsection{Relationship to the Literature}

This paper fits into two broad strands of the literature. First, a large empirical literature estimates the effects of macroeconomic factors and policy interventions on tuition and enrollment. Second, this paper relates to a growing body of literature employing structural models of higher education. With a few notable exceptions, these models focus on student demand and abstract from many distinguishing features of the supply side of the college market.

\subsubsection{Empirical Literature}

In discussing related work, we map our categorization of supply-side shocks, demand-side shocks, and macroeconomic forces into the existing empirical literature. For supply-side shocks, we analyze the impact of upward shifts in custodial (non-quality-enhancing) costs as well as changes in non-tuition revenues. The literature on Baumol's cost disease most closely relates to the former, while the literature analyzing the effect of the decline in state appropriations for higher education addresses the latter. 
Supply Shocks: Cost Disease The origins of cost disease emerge from seminal works by Baumol and Bowen (1966) and Baumol (1967). They lay out a clear mechanism: productivity increases in the economy at large drive up wages everywhere, which service sectors that lack productivity growth pass along by increasing their relative prices. Recently, Archibald and Feldman (2008) use cross-sectional industry data to forcefully advance the idea that cost and price increases in higher education closely mirror trends for other service industries that utilize highly educated labor. In short, they "reject the hypothesis that higher education costs follow an idiosyncratic path."

We find that the form of the cost increase matters. In particular, our estimates uncover a large increase in the fixed cost of operating a college from $\$ 12$ billion to $\$ 30$ billion in 2010 dollars. To pay for the higher fixed cost, the college lowers per-student investment and increases enrollment, which lowers average tuition by a composition effect.

Supply Shocks: Cuts in State Appropriations Heller (1999) suggests a negative relationship between state appropriations for higher education and tuition, asserting that "the higher the support provided by the state, the lower generally is the tuition paid by all students." Recent empirical work by Chakrabarty, Mabutas, and Zafar (2012), Koshal and Koshal (2000), and Titus, Simone, and Gupta (2010) support this hypothesis, but notably, Titus et al. (2010) show that this relationship only holds up in the short run. Lastly, in a large study commissioned by Congress in the 1998 re-authorization of the Higher Education Act of 1965, Cunningham, Wellman, Clinedinst, Merisotis, and Carroll (2001a) conclude that "Decreasing revenue from government appropriations was the most important factor associated with tuition increases at public 4-year institutions."

While our model finds little support for this idea in the aggregate - that is, lumping public and private colleges together - cuts in appropriations could potentially play a role in driving up public school tuition. Extending our model to incorporate heterogeneous colleges with detailed, disaggregated funding data will shed further light on this issue.

Demand Shocks: The Bennett Hypothesis For demand-side shocks, we focus on the effects of increased financial aid. We address the extent to which changes in loan limits and interest rates under the FSLP as well as expansions in state and federal grants to students drive up tuition - famously known as the Bennett hypothesis. A long line of empirical research has studied this hypothesis with mixed results.

Broadly speaking, we can divide the literature into those papers that find at least some support for this hypothesis and those that are highly skeptical. In the first group, McPherson and Shapiro (1991) use institutional data from 1978 - 1985 and find a positive relationship 
between aid and tuition at public universities but not at private universities. Singell and Stone (2007), using panel data from 1983 - 1996, find evidence for the Bennett hypothesis among top-ranked private institutions but not among public and lower-ranked private universities. They also found evidence in favor of the Bennett hypothesis for public out-of-state tuition. Rizzo and Ehrenberg (2004) come to the mirror opposite conclusion: "We find substantial evidence that increases in the generosity of the federal Pell Grant program, access to subsidized loans, and state need-based grant aid awards lead to increases in in-state tuition levels. However, we find no evidence that nonresident tuition is increased as a result of these programs." Turner (2012) shows that tax-based aid crowds out institutional aid almost onefor-one. Turner (2014) also finds that institutions capture some of the benefits of financial aid, but at a more modest $12 \%$ pass-through rate. Long (2004a) and Long (2004b) uncover evidence that institutions respond to greater aid by increasing charges, in some cases by up to $30 \%$ of the aid. Cellini and Goldin (2014) compare for-profit institutions that participate in federal student aid programs to those that do not participate. Institutions in the former group charge tuition that is about $78 \%$ higher than those in the latter group. Most recently, Lucca, Nadauld, and Shen (2015) find a 65\% pass-through effect for changes in federal subsidized loans and positive but smaller pass-through effects for changes in Pell Grants and unsubsidized loans.

In contrast to the previous literature, several papers reject or find little evidence for the Bennett hypothesis. For example, in their commissioned report for the 1998 re-authorization of the Higher Education Act, Cunningham et al. (2001a); Cunningham, Wellman, Clinedinst, Merisotis, and Carroll (2001b) conclude that "the models found no associations between most of the aid variables and changes in tuition in either the public or private not-for-profit sectors." These sentiments are echoed by Long (2006). Lastly, Frederick, Schmidt, and Davis (2012) study the response of community colleges to changes in federal aid and find little evidence of capture.

Our model likely exaggerates the impact of the Bennett hypothesis. As we discuss in section 4 , the monopolistic college engages in an implausibly high degree of rent extraction despite the presence of preference shocks. We suspect that more competition in our model of the higher education market would temper the magnitude of the tuition increase attributable to the Bennett hypothesis.

Macroeconomic Forces: Rising College Earnings Premia According to data from Autor et al. (2008), the college earnings premium increased from 58\% in the mid-1980s to $93 \%$ in 2005. While we remain agnostic about the cause of the increasing premium, several papers, including Autor et al. (2008), Katz and Murphy (1992), Goldin and Katz (2007), 
and Card and Lemieux (2001), ascribe it to skill-biased technological change combined with a fall in the relative supply of college graduates.

In recent work, Andrews, Li, and Lovenheim (2012) study the distribution of college earnings premia and find substantial heterogeneity attributable to variation in college quality. Hoekstra (2009) looks at earnings of white males ten to fifteen years after high school graduation and finds a premium of $20 \%$ for students who attended the most selective state university relative to those who barely missed the admissions cutoff and went elsewhere. Incorporating this heterogeneity in college earnings premia may help explain why tuition increases at selective schools (such as public and private research universities) have outpaced those at less selective schools.

\subsubsection{Quantitative Models of Higher Education}

Our paper also fits into a growing body of papers that employ structural models of higher education, such as Abbott, Gallipoli, Meghir, and Violante (2013), Athreya and Eberly (2013), Ionescu and Simpson (2015), Ionescu (2011), Garriga and Keightley (2010), Lochner and Monge-Naranjo (2011), Belley and Lochner (2007), and Keane and Wolpin (2001). In the interest of space, we discuss only the most closely related papers.

Recent work by Jones and Yang (2015) closely mirrors the objectives of this paper. They explore the role of skill-biased technical change in explaining the rise in college costs from 1961 to 2009. Their paper differs from ours along several dimensions. First, whereas they explore the effect of only one possible driver of higher college costs - namely, cost disease - we quantify the role of supply-side as well as demand-side shocks. Second, Jones and Yang (2015) analyze college costs — which increased by 35\% in real terms between 1987 and 2010 - whereas we address the increase in net tuition, which went up by $78 \%$. In terms of the model, we emphasize important details of the higher education market: peer effects, imperfect competition and price discrimination, subsidized and unsubsidized student loan borrowing, and the option for borrowers to default.

Our extension of the Epple et al. (2006) and Epple et al. (2013) framework to incorporate a life-cycle model with heterogeneous agents and incomplete markets features price discrimination, explicit peer effects, and rich post-graduation outcomes. Moreover, all of these features affect college enrollment, pricing, and financing decisions. Fillmore (2014) also analyzes a model of price discriminating colleges, but he treats peer effects in a reduced form way. Fu (2014) considers a rich game-theoretic framework of college admissions and enrollment but does not allow for price discrimination. 


\section{The Model}

The model embeds a college sector into a discrete time, open economy. A fixed measure of heterogeneous households enter the economy upon graduating high school, make college enrollment decisions, and then progress through their working life and into retirement. A monopolistic college with the ability to price discriminate transforms students into college graduates (albeit with dropout risk), and the government levies taxes to finance a student loan program.

\subsection{Households}

We sequentially describe the environment faced by youths, students, and, finally, workers and retirees. We immediately follow this discussion by a description of colleges in the model. Section 2.4 gives the decision problems for all agents in the economy.

\subsubsection{Youths}

Youths enter the economy at $j=1$ (corresponding to high school graduation at age 18), at which point they draw a two-dimensional vector of characteristics $s_{Y}=\left(x, y_{p}\right)$ consisting of academic ability $x$ and parental income $y_{p}$ from a distribution $G$. Youths make a once-andfor-all choice to either enroll in college or enter the workforce. In addition to the explicit pecuniary and non-pecuniary benefits of college that we will describe momentarily, youths receive a preference shock $\frac{1}{\alpha} \epsilon$ of attending college, where $\alpha>0$ and $\epsilon$ comes from a type 1 extreme distribution. Colleges cannot condition tuition on the preference shock.

\subsubsection{College Students}

Newly enrolled students enter college with their vector of characteristics $s_{Y}$ and a zero initial student loan balance, $l=0$. Colleges charge type-specific net tuition $T\left(s_{Y}\right)$ - equal to sticker price $\bar{T}$ minus institutional aid — which they hold fixed for the duration of enrollment.

Students also face non-tuition expenses $\phi$ that act as perfect substitutes for consumption $c$. Direct government grants $\zeta\left(T+\phi, E F C\left(s_{Y}\right)\right)$ offset some of the cost of attendance, where $E F C\left(s_{Y}\right)$ represents the expected family contribution - a formula used by the government to determine eligibility for need-based grants and loans. After taking into account both forms of aid, the net cost comes out to $N C O A\left(s_{Y}\right)=T\left(s_{Y}\right)+\phi-\zeta\left(T\left(s_{Y}\right)+\phi, E F C\left(s_{Y}\right)\right)$.

While enrolled, college students receive additive flow utility $v(q)$ which increases in college quality $q .{ }^{4}$ In order to graduate, students must complete $J_{Y}$ years of college. Students in class

\footnotetext{
${ }^{4}$ To improve tractability while computing the transition path, we assume students receive $v(q)$ each year
} 
$j$ return to college each year with probability $\pi_{j+1} \equiv \pi \mathbf{1}_{\left[j+1 \leq J_{Y}\right]}$; otherwise, they either drop out or graduate. ${ }^{5}$

Students can borrow through the Federal Student Loan Program (FLSP). Of primary interest, the FSLP features subsidized loans that do not accrue interest while the student is in college, where eligibility depends on financial need ( $N C O A$ less EFC). Since 1993, students can borrow additional funds up to the net cost of attendance using unsubsidized loans. Students face annual and aggregate limits for subsidized and combined borrowing.

Denote the annual and aggregate combined limits by $\bar{b}_{j}$ and $\bar{l}$, respectively. ${ }^{6}$ Because students can borrow only up to the net cost of attendance, their annual combined subsidized borrowing $b_{s}$ and unsubsidized borrowing $b_{u}$ must satisfy

$$
b_{s}+b_{u} \leq \min \left\{\bar{b}_{j}, \operatorname{NCOA}\left(s_{Y}\right)\right\}
$$

Similarly, define $\bar{b}_{j}^{s}$ as the statutory annual subsidized limit and $\bar{l}_{j}^{s}$ as the statutory aggregate subsidized limit. The actual amount $\tilde{b}_{j}^{s}\left(s_{Y}\right)$ that students can borrow in subsidized loans depends on their net cost of attendance and the expected family contribution, both of which vary with student type. Lastly, define $\tilde{l}_{j}^{s}\left(s_{Y}\right)$ as the maximum amount of subsidized loans that students can accumulate by year $j$ in college. Mathematically,

$$
\begin{aligned}
& \tilde{b}_{j}^{s}\left(s_{Y}\right)=\min \left\{\bar{b}_{j}^{s}, \max \left\{0, N C O A\left(s_{Y}\right)-E F C\left(s_{Y}\right)\right\}\right\} \\
& \tilde{l}_{j}^{s}\left(s_{Y}\right)=\min \left\{\bar{l}^{s}, \sum_{i=1}^{j} \tilde{b}_{i}^{s}\left(s_{Y}\right)\right\} .
\end{aligned}
$$

Given the superior financial terms of subsidized loans, we assume that students always exhaust their subsidized borrowing capacity before taking out any unsubsidized loans. Furthermore, to increase tractability, we assume that borrowers can carry over unused subsidized borrowing capacity into subsequent years. These two assumptions reduce the state space and simplify solving the student's debt portfolio choice problem.

Apart from loans, students have two other means of paying for college. First, they have earnings $e_{Y}$, which we treat as an endowment. ${ }^{7}$ Second, they receive a parental transfer $\xi E F C\left(s_{Y}\right)$, where $0 \leq \xi \leq 1$ is a parameter.

based on the college's quality $q$ at the time of initial enrollment. In the computation, we make the isomorphic assumption that students receive the net present value of $v(q)$ at the time of enrollment.

${ }^{5}$ We do not allow endogenous dropout for reasons of tractability.

${ }^{6}$ The aggregate limit caps maximum loan balances the period after borrowing, inclusive of interest.

${ }^{7}$ We abstract from labor supply choice and the trade-off between increased earnings and studying. 


\subsubsection{Workers/Retirees}

Working and retired households receive earnings $e$ that depend on a vector of characteristics $s$ that includes their level of education, age/retirement status, and a stochastic component. Each period, households face a proportional earnings tax $\tau$.

These households value consumption according to a period utility function $u(c)$ and discount the future at rate $\beta$. Workers with student loans face a loan interest rate of $i$ and amortization payments of $p(l, t)=l \frac{i(1+i)^{t-1}}{(1+i)^{t}-1}$, where $l$ represents the loan balance and $t$ the remaining duration. All households can use a discount bond to save at the risk-free rate $r^{*}$ and borrow up to the natural borrowing limit $\bar{a}$ at rate $r^{*}+\iota$, where $\iota$ is the interest premium on borrowing. The price of the bond is denoted $\left(1+r\left(a^{\prime}\right)\right)^{-1}$.

\subsection{Colleges}

There is one representative college. Following Epple et al. (2006), the college seeks to maximize its quality (or prestige), $q$, which depends on the average academic ability $\theta$ of the student body and on investment expenditures per student, $I$. The college's other expenses include non-quality-enhancing custodial costs $F+C\left(\left\{N_{j}\right\}_{j=1}^{J_{Y}}\right)$, where $F$ represents a fixed cost and $C$ is an increasing, twice-differentiable, convex function of enrollment $\left\{N_{j}\right\}_{j=1}^{J_{Y}}$.

The college finances its expenditures with two sources of revenue. First, the college has exogenous non-tuition revenue per student $E$, which includes endowment income, government appropriations, and revenues from auxiliary enterprises. Second, the college has endogenous tuition revenue, a function of enrollment decisions and type-specific net tuition $T\left(s_{Y}\right)$. The college is a non-profit and, given our assumption of an exogenous endowment stream, runs a balanced budget period-by-period. ${ }^{8}$

In order to avoid dealing with issues such as the college's discount factor-not to mention other difficulties associated with the transition path computation - we make the college problem static through four assumptions. First, we assume that college quality $q(\theta, I)$ depends on the academic ability of freshmen and investment expenditures per freshman student. ${ }^{9}$ Second, we assume that colleges face a quadratic cost function for each class given by

$$
F+C\left(\left\{N_{j}\right\}_{j=1}^{J_{Y}}\right)=F+\sum_{j=1}^{J_{Y}} c\left(n_{j}\right)
$$

where $N_{j}$ is the population measure in class $j$ ( $j=1$ for freshmen, $j=2$ for sophomores, etc.)

\footnotetext{
${ }^{8}$ Technically, the non-profit status of the college only implies that it cannot distribute dividends. However, we abstract from strategic decisions regarding endowment accumulation.

${ }^{9} \mathrm{We}$ assume the college commits to a level of $I$ for the duration of each incoming cohort's enrollment.
} 
and $n_{j} \equiv \frac{N_{j}}{1 / J}$ is the measure relative to the age-18 population (for scaling purposes in the estimation). Third, we assume the college has no access to credit markets. Last, we isolate the effect of current tuition and spending decisions on future budget conditions. Specifically, we assume that each year the college exchanges the rights to all future budget flows generated by contemporaneous tuition and expenditure decisions in exchange for an immediate net present value payment from the government. This last assumption implicitly rules out any "quality smoothing" on the part of the college and captures the fact that administrators typically have short tenures that may make borrowing against expected future flows challenging. ${ }^{10}$

\subsection{Legal Environment and Government Policy}

Consistent with U.S. law, workers in the model cannot liquidate their student loan debt through bankruptcy. However, they can skip payments and become delinquent. Upon initial default, workers enter delinquency status and face a proportional loan penalty of $\eta$ that accrues to their existing balance. In subsequent periods, delinquent workers face a proportional wage garnishment of $\gamma$ until they rehabilitate their loan by making a payment. Upon rehabilitation, the loan duration resets to the statutory value $t_{\max }$ and the amortization schedule adjusts accordingly.

The government operates the student loan program and finances itself with a combination of taxation on labor earnings, funds from loan repayments and wage garnishments, and the revenue flows generated by colleges discussed above. We assume that the government sets the tax rate $\tau$ to balance its budget period by period.

\subsection{Decision Problems}

Now we work backwards through the life cycle to describe the household decision problem. Afterward, we describe the college's optimization problem.

\subsubsection{Workers/Retirees}

Households start each period with asset position $a$, student loan balance $l$ and duration $t$, characteristics $s$, and delinquency status $f \in\{0,1\}$, where $f=0$ indicates good standing. Households in good standing on their student loans choose consumption, savings, and whether to make their scheduled loan payment. These households have the value function

$$
V(a, l, t, s, f=0)=\max \left\{V^{R}(a, l, t, s), V^{D}(a, l(1+\eta), s)\right\}
$$

\footnotetext{
${ }^{10}$ The average tenure of a dean is five years (Wolverton, Gmeich, Montez, and Nies, 2001).
} 
where $V^{R}$ is the utility of repayment and $V^{D}$ is the utility of delinquency. Note that $\eta$ increases the stock of outstanding debt in the case of a default.

Households in bad standing face the decision of whether to rehabilitate their loan or remain delinquent. Their value function is

$$
V(a, l, s, f=1)=\max \left\{V^{R}\left(a, l, t_{\max }, s\right), V^{D}(a, l, s)\right\}
$$

Household utility conditional on repayment or rehabilitation is given by

$$
\begin{gathered}
V^{R}(a, l, t, s)=\max _{c \geq 0, a^{\prime} \geq \underline{a}} u(c)+\beta \mathbb{E}_{s^{\prime} \mid s} V\left(a^{\prime}, l^{\prime}, t^{\prime}, s^{\prime}, f^{\prime}=0\right) \\
\text { subject to } \\
c+a^{\prime} /\left(1+r\left(a^{\prime}\right)\right)+p(l, t) \leq e(s)(1-\tau)+a \\
l^{\prime}=(l-p(l, t))(1+i), t^{\prime}=\max \{t-1,0\}
\end{gathered}
$$

The value of defaulting (if $f=0$ ) or not rehabilitating a loan (if $f=1$ ) is ${ }^{11}$

$$
\begin{gathered}
V^{D}(a, l, s)=\max _{c \geq 0, a^{\prime} \geq \underline{a}} u(c)+\beta \mathbb{E}_{s^{\prime} \mid s} V\left(a^{\prime}, l^{\prime}, s^{\prime}, f^{\prime}=1\right) \\
\text { subject to } \\
c+a^{\prime} /\left(1+r\left(a^{\prime}\right)\right) \leq e(s)(1-\tau)(1-\gamma)+a \\
l^{\prime}=\max \{0,(l-e(s)(1-\tau) \gamma)(1+i)\}
\end{gathered}
$$

In the last period of life, households have no continuation utility and no ability to borrow or save. We allow households to die with student loan debt.

\subsubsection{College Students}

College students with characteristics $s_{Y}=\left(x, y_{p}\right)$ and debt $l$ choose consumption and additional student loans, $l^{\prime} \geq l$. In particular, we assume that students do not pay back their loans while still in college, which speeds up computation. We also introduce an annual limit $\bar{b}_{j}^{u}$ for unsubsidized borrowing that equals either the combined limit or zero (the latter case captures the pre-1993 environment where there were no unsubsidized loans).

\footnotetext{
${ }^{11}$ In the case of a default, note that $\eta$ has already been applied to the loan balance in (4).
} 
Taking college quality $q$ and the net tuition function $T(\cdot)$ as given, students solve

$$
\begin{aligned}
& Y_{j}\left(l, s_{Y} ; T, q\right)=\max _{c \geq 0, l^{\prime} \geq l} u(c+\phi)+v(q)+\beta\left[\begin{array}{c}
\pi_{j+1} Y_{j+1}\left(l^{\prime}, s_{Y} ; T\right)+\left(1-\pi_{j+1}\right) \\
\times \mathbb{E}_{s^{\prime} \mid j, s_{Y}} V\left(a^{\prime}=0, l^{\prime}, t_{\text {max }}, s^{\prime}, 0\right)
\end{array}\right] \\
& \text { subject to } \\
& c+N C O A\left(s_{Y}\right) \leq e_{Y}+\xi E F C\left(s_{Y}\right)+b_{s}+b_{u} \\
& \left(l_{s}^{\prime}, l_{u}^{\prime}\right)= \begin{cases}\left(l^{\prime}, 0\right) & \text { if } l^{\prime} \leq \tilde{l}_{j}^{s}\left(s_{Y}\right) \\
\left(\tilde{l}_{j}^{s}\left(s_{Y}\right), l^{\prime}-\tilde{l}_{j}^{s}\left(s_{Y}\right)\right) & \text { otherwise }\end{cases} \\
& \left(l_{s}, l_{u}\right)= \begin{cases}(l, 0) & \text { if } l \leq \tilde{l}_{j-1}^{s}\left(s_{Y}\right) \\
\left(\tilde{l}_{j-1}^{s}\left(s_{Y}\right), l-\tilde{l}_{j-1}^{s}\left(s_{Y}\right)\right) & \text { otherwise }\end{cases} \\
& b_{s}=l_{s}^{\prime}-l_{s} \\
& b_{u}=\frac{l_{u}^{\prime}}{1+i}-l_{u} \\
& l_{s}^{\prime}+\frac{l_{u}^{\prime}}{1+i} \leq \bar{l} \\
& b_{u} \leq \min \left\{\bar{b}_{j}^{u}, N C O A\left(s_{Y}\right)\right\} \\
& b_{s}+b_{u} \leq \min \left\{\bar{b}_{j}, N C O A\left(s_{Y}\right)\right\}
\end{aligned}
$$

Note from these equations that our setup allows us to easily decompose student debt into its subsidized and unsubsidized components. We deflate $l_{u}^{\prime}$ by $1+i$ in the aggregate borrowing constraint because the loan limit is inclusive of interest accrued by unsubsidized loans.

\subsubsection{Youth}

Youth making their college enrollment decisions have value function

$$
\max \{\underbrace{\mathbb{E}_{s \mid s_{Y}} V_{1}(a=0, l=0, t=0, s)}_{\text {enter the labor force }}, \underbrace{Y_{1}\left(l=0, s_{Y} ; T, q\right)+\frac{1}{\alpha} \epsilon}_{\text {attend college }}\}
$$

where $\epsilon$ denotes the college preference shock and $s$ is the initial worker characteristics draw. 


\subsubsection{Colleges}

The college problem can be written as

$$
\begin{gathered}
\max _{I \geq 0, T(\cdot)} q(\theta, I) \\
\text { subject to } \\
\mathcal{E}+\mathcal{T}=F+\mathcal{C}\left(N_{1}\right)+\mathcal{I} \\
N_{1}=\int \mathbb{P}\left(\operatorname{enroll} \mid s_{Y} ; T(\cdot), q\right) d \mu_{0}\left(s_{Y}\right) \\
\theta N_{1}=\int x\left(s_{Y}\right) \mathbb{P}\left(\operatorname{enroll} \mid s_{Y} ; T(\cdot), q\right) d \mu_{0}\left(s_{Y}\right) \\
\mathcal{T}=\sum_{j=1}^{J_{Y}} \frac{\pi^{j-1} \int T\left(s_{Y}\right) \mathbb{P}\left(\operatorname{enroll} \mid s_{Y} ; T(\cdot), q\right) d \mu_{0}\left(s_{Y}\right)}{\left(1+r^{*}\right)^{j-1}} \\
\mathcal{E}=E \sum_{j=1}^{J_{Y}} \frac{\pi^{j-1} N_{1}}{\left(1+r^{*}\right)^{j-1}} \\
\mathcal{C}\left(N_{1}\right)=\sum_{j=1}^{J_{Y}} \frac{c\left(\pi^{j-1} \frac{N_{1}}{1 / J}\right)}{\left(1+r^{*}\right)^{j-1}} \\
\mathcal{I}=I \sum_{j=1}^{J_{Y}} \frac{\pi^{j-1} N_{1}}{\left(1+r^{*}\right)^{j-1}}
\end{gathered}
$$

where $\mu_{0}\left(s_{Y}\right) \equiv G\left(s_{Y}\right) / J$ is the distribution of characteristics across the age-18 population.

The first constraint reflects the college balanced budget requirement, while the remaining constraints establish the definitions of enrollment, average freshman ability, tuition revenues, non-tuition revenues, custodial costs, and investment expenditures, respectively.

\subsection{Steady State Equilibrium}

A steady state equilibrium consists of household value and policy functions, a tax rate, college policies and quality, and a distribution of households such that:

1. The household value and policy functions satisfy $(4-9)$.

2. The college policies and quality satisfy (10).

3. The government budget balances.

4. The distribution is invariant. 


\section{Data and Estimation}

We calibrate the model to replicate key features of the U.S. economy and higher education sector in 1987. These initial conditions set the stage for the results section, which feeds in the observed changes between 1987 and 2010 described in the introduction to assess their impact on equilibrium tuition. We proceed through our description of the calibration and estimation in the same order as we described the model.

\subsection{Households}

\subsubsection{Youth}

We determine the distribution $G$ of youth characteristics $s_{Y}=\left(x, y_{p}\right)$ using data from the NLSY97. The ability measure comes from percentiles on the ASVAB aptitude test. For parental income, we use the household income measure from 1997 in those cases where the data correspond to the parents rather than the youth (98.0\% of cases).

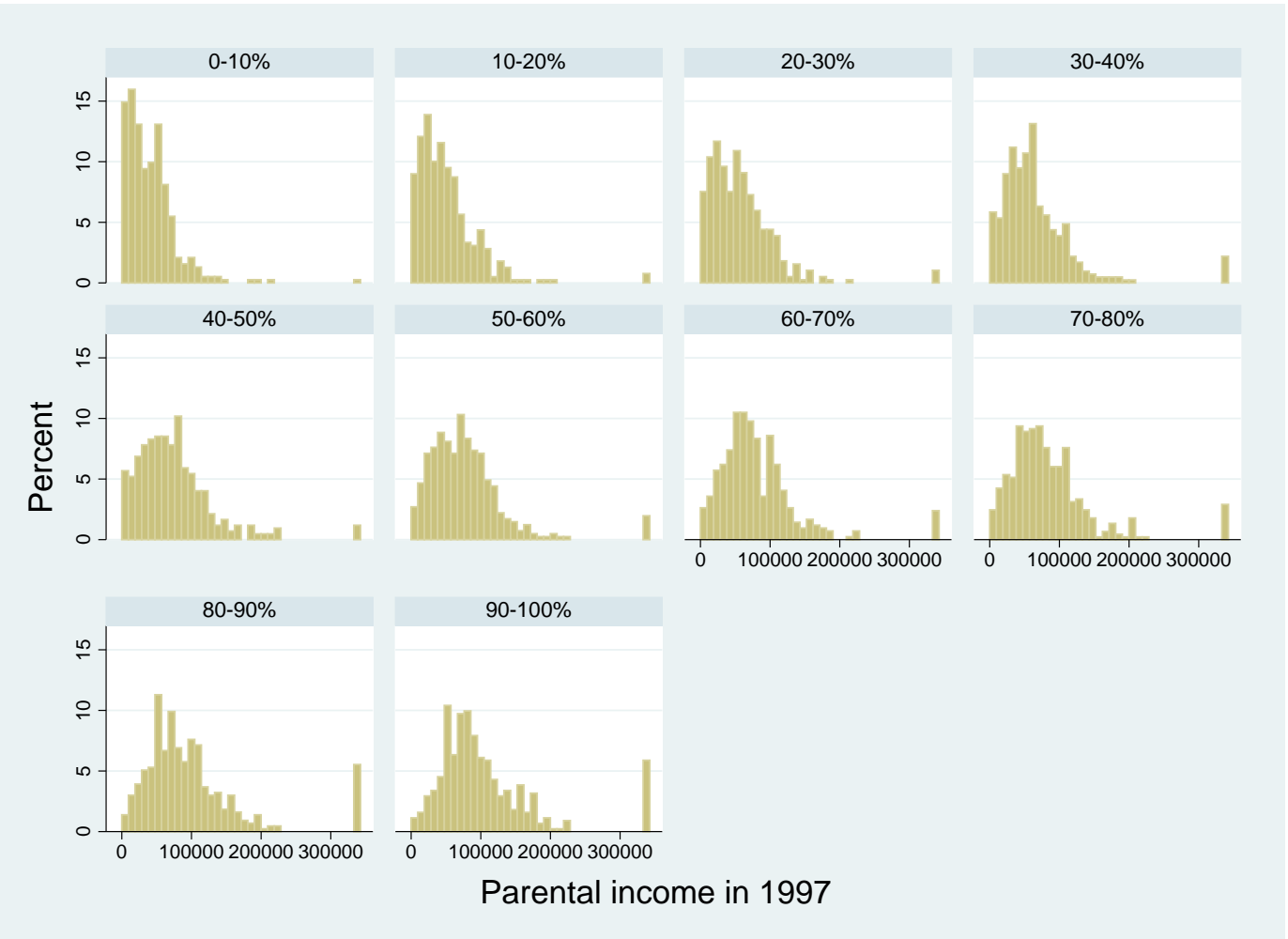

Figure 1: Distribution of Parental Income by Ability Decile

Figure 1 displays histograms of the parental income distribution by ability level. In each case, parental income resembles a truncated normal distribution. To handle truncation from above due to top-coding and truncation from below, we estimate a Tobit model 
where parental income depends on ability. Specifically, we estimate

$$
\begin{gathered}
y_{i}^{*}=\beta_{0}+\beta_{1} x_{i}+\varepsilon_{i} \\
y_{i}=\min \left\{\max \left\{0, y_{i}^{*}\right\}, \bar{y}\right\}
\end{gathered}
$$

where $y_{i}$ is the observed parental income, $y_{i}^{*}$ is the "true" parental income, and $\varepsilon_{i} \sim$ $N\left(0, \sigma^{2}\right) .{ }^{12}$ The parameter $\bar{y}$ corresponds to the $2 \%$ top-coded level implemented in the NLSY97 (we find $\bar{y}=\$ 226,546$ in 2010 dollars). In 2010 dollars, we find $\beta_{0}=\$ 40,006$, $\beta_{1}=\$ 614.6$, and $\sigma=\$ 48,012$, with standard errors of $\$ 1,529, \$ 25.95$, and $\$ 543.4$, respectively. By the construction of $x$ in NLSY97, $x \sim U[0,100]$. Hence, our estimation implies that, all else equal, parents of children at the top of the ability distribution earn $\$ 152,900$ more on average than parents of children at the bottom of the ability distribution. We assume the joint distribution is time invariant.

\begin{tabular}{cccc}
\hline \hline & Ability & Parental Income & Enrollment \\
\hline Ability & 1.0000 & & \\
Parental Income & 0.3164 & 1.0000 & \\
Enrollment & 0.5216 & 0.2952 & 1.0000 \\
\hline \hline
\end{tabular}

Table 1: Correlations Between Ability, Parental Income, and Enrollment

Table 1 reports the correlation between ability, observed parental income, and enrollment. All the correlations are significant at more than a $99.9 \%$ confidence level. We use the correlation between ability and enrollment as a calibration target and the correlation between enrollment and parental income as an untargeted prediction of the model.

\subsubsection{College Students}

For our specification of the expected family contribution function $\operatorname{EFC}\left(s_{Y}\right)$, we use an approximation from Epple et al. (2013) to the true statutory formula. Specifically, we assume a mapping between raw and adjusted gross parental income of $\tilde{y}\left(y_{p}\right)=y(1+.07 \cdot \mathbf{1}[y \geq$ $\$ 50000])$ and an EFC formula given by $\operatorname{EFC}\left(y_{p}\right)=\max \left\{\tilde{y}\left(y_{p}\right) / 5.5-\$ 5,000, \tilde{y}\left(y_{p}\right) / 3.2-\right.$ $\$ 16,000,0\}$ in 2009 dollars.

We assume that the government grants $\zeta\left(T+\phi, E F C\left(s_{Y}\right)\right)$ are given by

$$
\zeta\left(T\left(s_{Y}\right)+\phi, E F C\left(s_{Y}\right)\right)=\left\{\begin{array}{ll}
\zeta^{F} \bar{\zeta} & \text { if } \zeta^{F} \bar{\zeta} \leq T\left(s_{Y}\right)+\phi-E F C\left(s_{Y}\right) \\
0 & \text { otherwise }
\end{array},\right.
$$

\footnotetext{
${ }^{12}$ The NLSY79 top-codes at the $2 \%$ level by replacing the true value with the conditional mean of the top $2 \%$. In this estimation, we bound the observed value at the $2 \%$ threshold value.
} 
which reflects the progressive nature of federal grants. First, we estimate the average value of government grants $\bar{\zeta}$ from the college-level Integrated Postsecondary Education Data (IPEDS) published by the National Center for Education Statistics (NCES). Then, we calibrate $\zeta^{F} \geq 1$ to match average grants per student, $\bar{\zeta}$, in the initial steady state. Over the transition path we keep $\zeta^{F}$ constant but vary $\bar{\zeta}$.

The utility function $u(c)=\frac{c^{1-\sigma}}{1-\sigma}$ for students as well as workers and retirees features constant relative risk aversion. We use the standard parametrization of $\sigma=2$ and $\beta=0.96$. We assume utility from college quality is linear, $v(q)=q$ (and so all curvature comes from the production function $q(\theta, I))$.

To determine student earnings $e_{Y}$ while in college, we again turn to the NLSY97. For our sample, students enrolled in a 4-year college earn on average $\$ 7,128$ (in 2010 dollars). ${ }^{13}$ We convert this to model units and set $e^{Y}$ equal to it. The mapping from dollars into model units is discussed in section B.1.

Recall that the annual retention rate satisfies $\pi_{j+1}=\pi \mathbf{1}\left[j+1 \leq J_{Y}\right]$, which implies constant progression probabilities for students in years $1, \cdots, J_{Y}-1$. Students in their last year, which we set to $J_{Y}=5$, successfully graduate and earn a diploma with this same probability. We set $\pi=0.556^{1 / J_{Y}}$ to match the aggregate completion rate of $55.6 \%$ reported by Ionescu and Simpson (2015).

Lastly, we allow the non-tuition cost of attending college $\phi$, which plays a significant part in determining eligibility for subsidized loans, to vary over the transition path. We measure $\phi$ using room-and-board estimates from the NCES (nce, 2015c).

\subsubsection{Workers/Retirees}

The earnings process for working households follows

$$
\begin{gathered}
\log e_{i j t}=\lambda_{t} h_{i} / J_{Y}+\mu_{j}+z_{i j}+\nu \\
z_{i, j+1}=\rho z_{i j}+\eta_{i, j+1} \\
\eta_{i, j+1} \sim N\left(0, \sigma_{z}^{2}\right)
\end{gathered}
$$

where $h_{i}$ is the number of completed years of college, $i$ is an individual identifier, $j$ is age, and $t$ is time. Households who begin working at age $j$ draw $z_{i j}$ from an unconditional distribution with mean zero and and variance $\sigma_{z}^{2}\left(1+\ldots+\rho^{2(j-1)}\right)$. For the persistent shock, we use

\footnotetext{
${ }^{13}$ Students work an average of 824 hours a year in the NLSY97. Using different data, Ionescu (2011) reports similar results of $46 \%$ of full-time college students working with mean earnings (for workers) of $\$ 20,431$ in 2007 dollars.
} 
Storesletten, Telmer, and Yaron (2004)'s estimates in setting $\left(\rho, \sigma_{z}\right)=(0.952,0.168) .{ }^{14}$ The deterministic earnings profile $\mu_{j}$ is a cubic function of age with coefficients also taken from Storesletten et al. (2004). ${ }^{15}$

In the model, $\lambda_{t}$ represents the earnings premium for college graduates relative to high school graduates. We compute $\lambda_{t}$ using the estimates from Autor et al. (2008), which range from roughly 0.43 in the 1960 s and 1970 s to 0.65 in the early 2000s. To deal with the fact that Autor et al. (2008) estimate values only up until 2005, we fit a quadratic polynomial over 1988-2005 and extrapolate for 2006-2010. ${ }^{16}$ We use the fitted values (both in-sample and out-of-sample) for $\lambda_{t}$, and they are presented in table 4 (see appendix B.2 for a comparison of the raw and fitted values).

Retired households $\left(j>J_{R}=48\right)$ have constant earnings given by $\log e_{i j t}=\log (0.5)+$ $\lambda_{t} h_{i} / J_{Y}+\mu_{J_{R}}+\nu$, which yields an average replacement rate of roughly $50 \%$.

\subsection{Legal Environment and Government Policy}

We set the duration of loan repayment to its value in the Federal Student Loan Program, $t_{\max }=10$. Two parameters - the loan balance penalty $\eta$ and garnishment rate $\gamma$-control the cost of student loan delinquency. Various changes in student loan default laws between 1987 and 2010 render obtaining values for these parameters less than straightforward. ${ }^{17}$ Our approach sets $\eta=0.05$, (which is half the value in Ionescu, 2011, and only a fifth of the current statutory maximum) and then pins down $\gamma$ in the joint calibration to match the $17.6 \%$ student loan default rate in 1987.

\subsection{Colleges}

We need to parametrize and provide estimates for the per-student endowment $E$, the quality production function $q(\theta, I)$, and custodial costs $F+C\left(\left\{N_{j}\right\}_{j=1}^{J_{Y}}\right)$. We set the per-student endowment $E$ equal to non-tuition revenues per FTE student in the 1987 IPEDS data, and then we vary $E$ along the transition path. Figure 2 plots the time series for $E$ and other key aggregates. For college quality, we follow Epple et al. (2013) and choose a Cobb Douglas functional form, $q(\theta, I)=\chi_{q} \theta^{\chi_{\theta}} I^{\chi_{I}}$, where $\chi_{I}=1-\chi_{\theta} \cdot{ }^{18}$

\footnotetext{
${ }^{14}$ Storesletten et al. (2004) let $\sigma$ vary with the business cycle and estimate $\sigma=.211$ for recessions and $\sigma=.125$ for expansions. We average these.

${ }^{15}$ In principle, one could include a cohort-specific term that allows for average log earnings in the economy to grow over time. However, we found that such a term is negligible in the data as we show in section B.1.

${ }^{16}$ The "1987" college premium corresponds to the average from 1981 to 1987.

${ }^{17}$ See Ionescu (2011) for changes in student loan default laws.

${ }^{18}$ In principle, $q(\theta, I)$ need not satisfy constant returns to scale. With one college, it is difficult to pin down - using only steady state information - what the returns should be. With multiple colleges, dispersion
} 
Trends of key aggregates

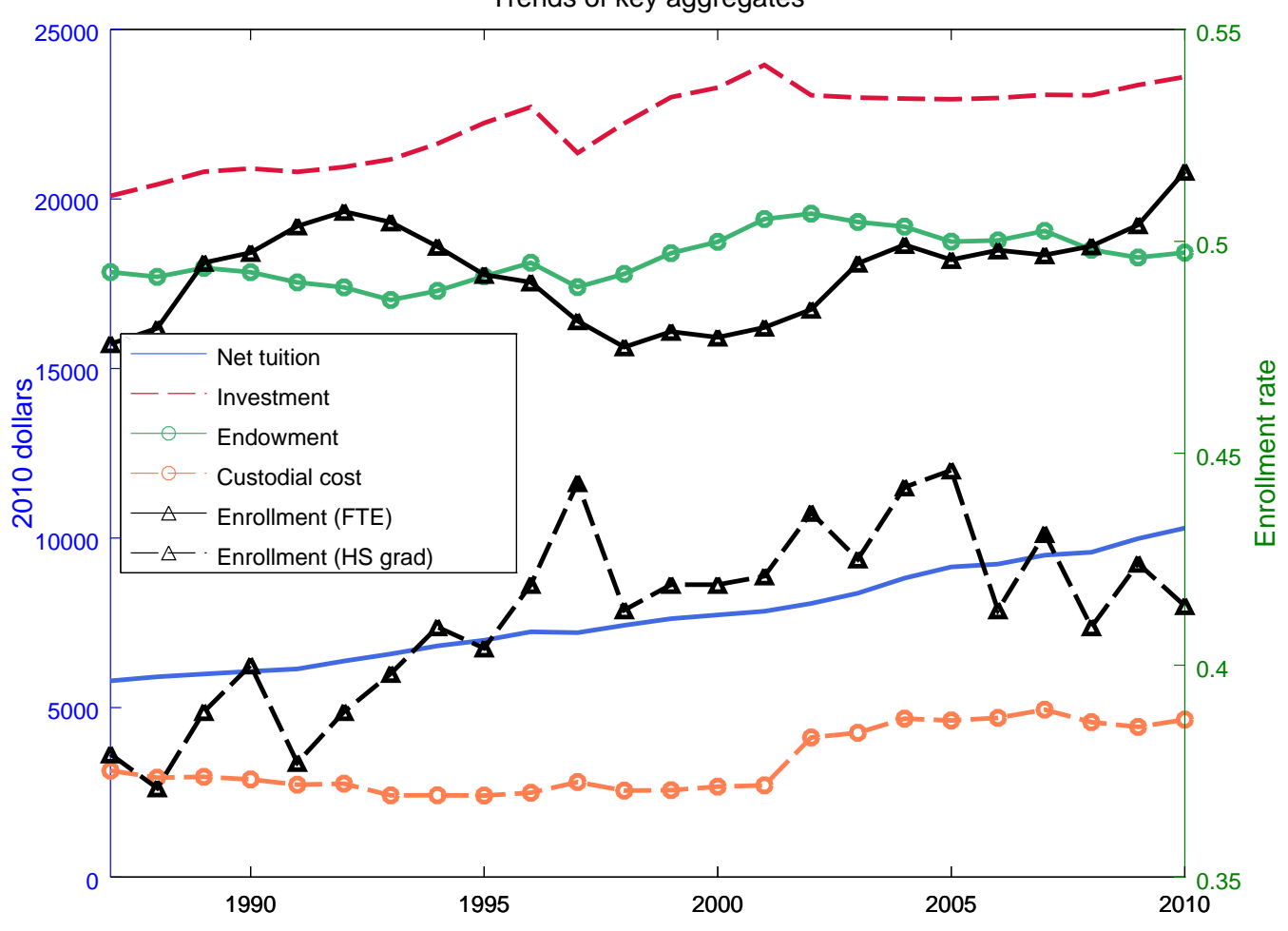

Figure 2: College Cost, Expenditure, and Enrollment Trends. 
The local first-order conditions of the college problem provide some insight into calibrating $\chi_{\theta}$ and $\chi_{q}$. The key tuition-pricing condition comes out to

$$
T\left(s_{Y}\right)+\frac{\mathbb{P}\left(\text { enroll } \mid s_{Y} ; T(\cdot), q\right)}{\partial \mathbb{P}\left(\text { enroll } \mid s_{Y} ; T(\cdot), q\right) / \partial T}=C^{\prime}(N)+I+\frac{q_{\theta}}{q_{I}}\left(\theta-x\left(s_{Y}\right)\right)
$$

where $\mathbb{P}\left(\right.$ enroll $\left.\mid s_{Y} ; T(\cdot), q\right)$ comes from the decision rule of youths for whether to attend college, taking into account the idiosyncratic preference shock $\epsilon$. Epple et al. (2013) label the collected right-hand side terms the "effective marginal cost" $E M C$ of a type- $s_{Y}$ student, which captures the fact that students act both as customers and as inputs to the production of quality (an argument put forth by Winston, 1999, and others). The above equation states that colleges admit any student to whom they can charge at least $\operatorname{EMC}\left(s_{Y}\right)$.

With our Cobb-Douglas specification, $\frac{q_{\theta}}{q_{I}}=\frac{\chi_{\theta}}{\chi_{I}} \frac{I}{\theta}=\frac{\chi_{\theta}}{1-\chi_{\theta}} \frac{I}{\theta}$. The degree to which $E M C\left(s_{Y}\right)$, and therefore tuition $T\left(s_{Y}\right)$, varies by student type depends on $\chi_{\theta}$. This price discrimination generates cross-sectional enrollment patterns that we use to target $\chi_{\theta}$ and $\chi_{q}$. Specifically, we target overall enrollment and the correlation between parental income and enrollment.

\subsubsection{Cost Function Estimation}

Like in Epple et al. (2006), we estimate the college's custodial cost function directly. In particular, we assume that the custodial costs by class, $c(n)$, have the functional form $C^{1} n+$ $C^{2} n^{2}$. When we explicitly allow for time-varying coefficients, custodial costs satisfy

$$
F_{t}+C_{t}\left(\left\{N_{j t}\right\}_{j=1}^{J_{Y}}\right)=F_{t}+C_{t}^{1} \sum_{j=1}^{J_{Y}} n_{j t}+C_{t}^{2} \sum_{j=1}^{J_{Y}} n_{j t}^{2}
$$

where $n_{j t} \equiv \frac{N_{j t}}{1 / J}$ is class $j$ enrollment in year $t$ relative to the age-18 population.

To identify $F_{t}, C_{t}^{1}$, and $C_{t}^{2}$, we estimate cost functions for individual colleges using IPEDS data and then aggregate them. Let college $i$ 's cost function at time $t$ be given by

$$
\mathfrak{c}_{i t}=\alpha_{i}+\mathfrak{c}_{t}^{0}+\mathfrak{c}_{t}^{1} \sum_{j=1}^{J_{Y}} n_{i j t}+\mathfrak{c}_{t}^{2} \sum_{j=1}^{J_{Y}} n_{i j t}^{2}+\varepsilon_{i t}
$$

Here, $\alpha_{i}$ is a fixed effect and both $\alpha_{i}$ and $\varepsilon_{i t}$ are i.i.d. normally distributed with mean zero.

The IPEDS data contains enrollment information but not its composition by class. To deal with this problem and to create consistency with the model, we assume a constant retention rate $\pi$ and a five-year college term, $J_{Y}=5$. Given $\pi, J_{Y}$, and total FTE enrollment in $\theta$ and $I$ translates into dispersion in $q$ that is controlled by returns to scale. 
data by school relative to the age 18 population, we calculate implied class $j$ enrollment as $n_{i j t}=\pi^{j-1} F T E_{i t} / \sum_{\iota=1}^{J_{Y}} \pi^{\iota-1}$. Thus, the two summation terms in the cost function come out to $\sum_{j=1}^{J_{Y}} n_{i j t}=F T E_{i t}$ and $\sum_{j=1}^{J_{Y}} n_{i j t}^{2}=F T E_{i t}^{2} \sum_{j=1}^{J_{Y}} \pi^{2(j-1)} /\left(\sum_{j=1}^{J_{Y}} \pi^{j-1}\right)^{2}$. As a result,

$$
\mathfrak{c}_{i t}=\alpha_{i}+\mathfrak{c}_{t}^{0}+\mathfrak{c}_{t}^{1} F T E_{i t}+\mathfrak{c}_{t}^{2} F T E_{i t}^{2} \frac{\sum_{j=1}^{J_{Y}} \pi^{2(j-1)}}{\left(\sum_{j=1}^{J_{Y}} \pi^{j-1}\right)^{2}}+\varepsilon_{i t} .
$$

As in Epple et al. (2006), we measure custodial costs as a residual in the college budget constraint, which gives us

$$
\mathfrak{c}_{i t} \equiv \mathfrak{e}_{i t}+\mathfrak{t}_{i t}-\mathfrak{i}_{i t}
$$

The first term, $\mathfrak{e}_{i t}$, represents total non-tuition revenue in IPEDS (which consists mostly of endowment revenue and government appropriations), while $\mathfrak{t}_{i t}$ and $\mathfrak{i}_{i t}$ equal net tuition revenues and total education and general $(E \& G)$ expenditures, respectively. Intuitively, our cost measure reflects the fact that, holding investment $\mathfrak{i}_{i t}$ constant, higher costs must accompany any observed increase in revenues in order to maintain a balanced budget. Consequently, any factors related to Baumol's cost disease, such as escalating faculty wages, appear in $\mathfrak{c}_{i t}$. Using these definitions, we run the fixed effects panel regression above to obtain $\left\{\left(\mathfrak{c}_{t}^{0}, \mathfrak{c}_{t}^{1}, \mathfrak{c}_{t}^{2}\right)\right\}_{t=1987}^{2010}$.

To translate the individual cost function estimates into the aggregate cost function, we sum costs over colleges. In particular, to calculate the total cost of educating $\left\{N_{j t}\right\}_{j=1}^{J_{Y}}$ students, we assume students sort across colleges $i=1, \ldots, K$ in proportion to the observed share in the data. ${ }^{19}$ Define $s_{i j t} \equiv N_{i j t} / N_{j t}=n_{i j t} / n_{j t}$ as the share of students in class $j$ at time $t$ who attend college $i$. From our assumption of geometric retention probabilities, this share does not vary with $j$, i.e., $s_{i j t}=s_{i t}$. Thus, $N_{i j t}=s_{i t} N_{j t}$ and $n_{i j t}=s_{i t} n_{j t}$ for all $j$, which gives $\mathrm{us}^{20}$

$$
F_{t}+C_{t}\left(\left\{N_{j t}\right\}_{j=1}^{J_{Y}}\right)=K \mathfrak{c}_{t}^{0}+\mathfrak{c}_{t}^{1} \sum_{j=1}^{J_{Y}} n_{j t}+\left(\mathfrak{c}_{t}^{2} \sum_{i=1}^{K} s_{i t}^{2}\right) \sum_{j=1}^{J_{Y}} n_{j t}^{2}
$$

This mapping between individual colleges and the representative college yields $F_{t}=K \mathfrak{c}_{t}^{0}$, $C_{t}^{1}=\mathfrak{c}_{t}^{1}$, and $C_{t}^{2}=\mathfrak{c}_{t}^{2} \sum_{i} s_{i t}^{2}$.

Table 2 presents the estimates. We found it necessary to impose $\mathfrak{c}_{t}^{1}=0$ to ensure an increasing aggregate cost function over the relevant range of $N$. Figure 3 plots the aggregate cost function over time and circles the realized values from each year.

\footnotetext{
${ }^{19}$ We allow $K$ to vary over time in the estimation (it is the number of colleges in the sample) but treat it as fixed here to simplify the exposition.

${ }^{20}$ We assume that $\sum_{i} \alpha_{i}=0$ and $\sum_{i} \varepsilon_{i t}=0$, where the first assumption is required for identification in the fixed effects regression.
} 


\begin{tabular}{|c|c|c|c|c|c|c|}
\hline$t$ & \multicolumn{2}{|c|}{$\overline{c_{t}^{0}}$} & \multicolumn{2}{|c|}{$\mathfrak{c}_{t}^{2} / 1000$} & $F_{t}$ & $\overline{\overline{C_{t}^{2}}}$ \\
\hline 1987 & 13.0 & $(1.6)$ & 147 & $(65)$ & 12259 & 534 \\
\hline 1988 & 12.6 & $(1.6)$ & 176 & (66) & 12212 & 627 \\
\hline 1989 & 13.5 & $(1.5)$ & 186 & (64) & 13783 & 636 \\
\hline 1990 & 12.8 & $(1.5)$ & 218 & $(62)$ & 13474 & 733 \\
\hline 1991 & 12.5 & $(1.5)$ & 173 & $(60)$ & 13073 & 585 \\
\hline 1992 & 13.4 & $(1.5)$ & 208 & $(60)$ & 14472 & 683 \\
\hline 1993 & 12.7 & $(1.5)$ & 191 & (60) & 13806 & 618 \\
\hline 1994 & 12.7 & $(1.4)$ & 216 & (59) & 13981 & 694 \\
\hline 1995 & 12.4 & $(1.4)$ & 230 & $(57)$ & 13573 & 752 \\
\hline 1996 & 10.9 & $(1.5)$ & 340 & (61) & 11657 & 1116 \\
\hline 1997 & 13.5 & $(1.5)$ & 287 & (63) & 12921 & 984 \\
\hline 1998 & 13.2 & $(1.6)$ & 296 & $(65)$ & 12477 & 1024 \\
\hline 1999 & 12.9 & $(1.6)$ & 325 & (68) & 12116 & 1107 \\
\hline 2000 & 14.4 & $(1.6)$ & 376 & (73) & 13883 & 1251 \\
\hline 2001 & 14.1 & $(1.6)$ & 345 & (71) & 13649 & 1147 \\
\hline 2002 & 21.7 & $(1.6)$ & 726 & (71) & 20851 & 2411 \\
\hline 2003 & 23.2 & $(1.6)$ & 707 & $(65)$ & 22209 & 2364 \\
\hline 2004 & 26.8 & $(1.6)$ & 810 & (63) & 25369 & 2745 \\
\hline 2005 & 27.9 & $(1.6)$ & 814 & $(60)$ & 26326 & 2793 \\
\hline 2006 & 28.7 & $(1.6)$ & 878 & $(60)$ & 26983 & 3011 \\
\hline 2007 & 30.0 & $(1.6)$ & 977 & $(59)$ & 28325 & 3356 \\
\hline 2008 & 30.0 & $(1.6)$ & 851 & $(57)$ & 28357 & 2949 \\
\hline 2009 & 30.2 & $(1.6)$ & 730 & (54) & 27912 & 2606 \\
\hline 2010 & 32.9 & $(1.6)$ & 691 & (49) & 30051 & 2516 \\
\hline $\begin{array}{l}\text { R-squ } \\
\text { Obse } \\
\text { Note } \\
\text { millic }\end{array}$ & ed: & $\begin{array}{l}\text { thin } \\
2371\end{array}$ & 年 & 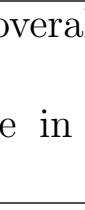 & 0.130 . & \\
\hline
\end{tabular}

Table 2: Cost Curve Estimates 


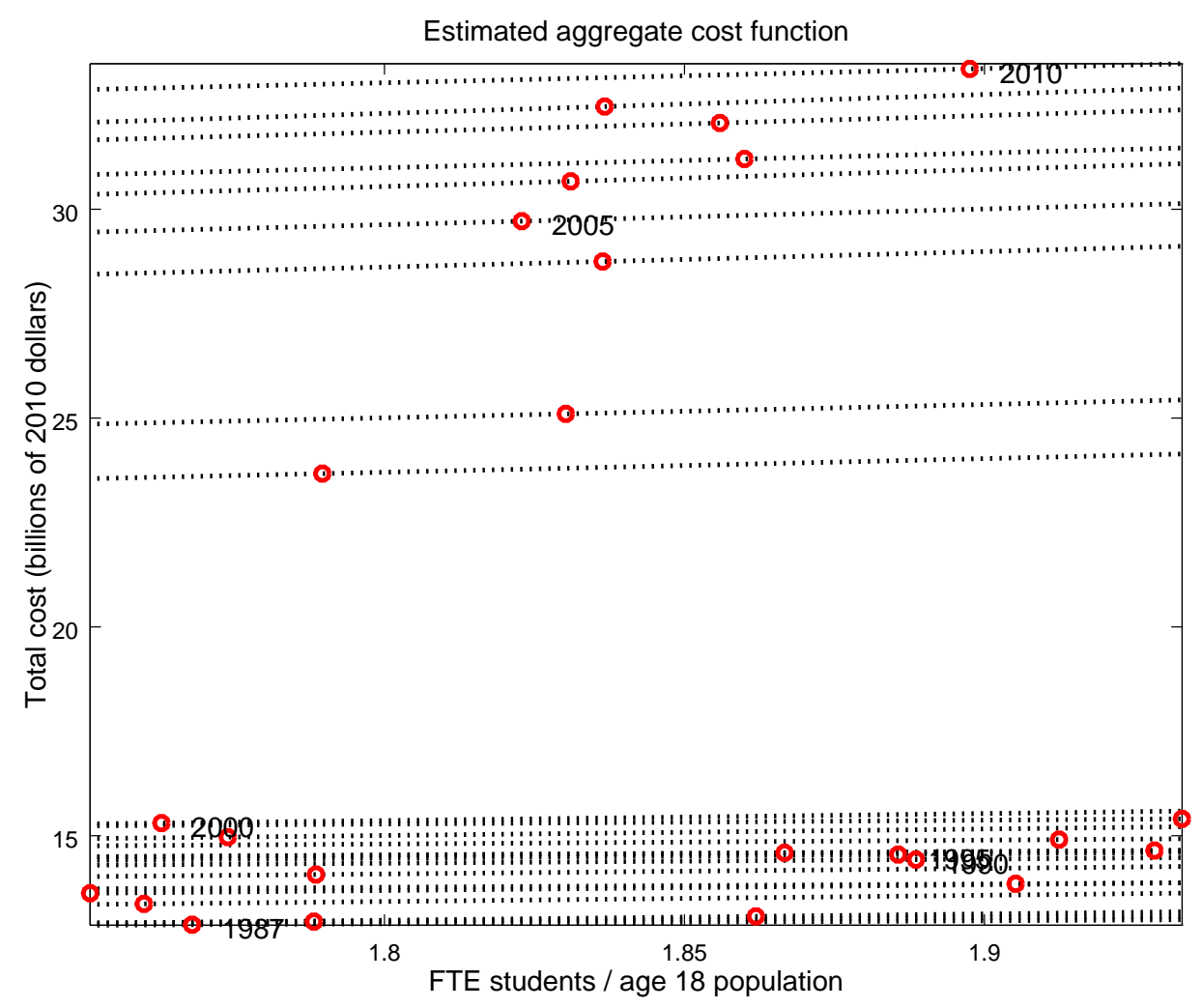

Figure 3: Estimated Aggregate Cost Function by Year 


\subsection{Joint Calibration}

We determine the remaining parameters $\left(\nu, \xi, \gamma, \chi_{\theta}, \chi_{q}, \zeta^{F}, \alpha\right)$ jointly such that the initial steady state matches the following moments in 1987: average earnings, average net tuition, the two-year cohort default rate, the correlation between parental income and enrollment, the enrollment rate, the average grant size, and the percent of students with loans. ${ }^{21}$

Table 3 summarizes the calibration. Note that, while the table associates each parameter in the joint calibration with an individual moment, the calibration identifies the parameters simultaneously, rather than separately. We discuss model fit in the next section.

Table 3: Model Calibration

\begin{tabular}{|c|c|c|c|c|c|}
\hline Description & Parameter & Value & Data & Model & Target/Reason \\
\hline \multicolumn{6}{|c|}{ Calibration: Independent Parameters } \\
\hline Discount factor & $\beta$ & 0.96 & & & Standard \\
\hline Risk aversion & $\sigma$ & 2 & & & Standard \\
\hline Savings interest rate & $r^{*}$ & 0.02 & & & Standard \\
\hline Borrowing premium & $\iota$ & 0.107 & & & $12.7 \%$ rate on borrowing \\
\hline Earnings in college & $e_{Y}$ & $\$ 7,128_{2010}$ & & & NLSY97 \\
\hline Loan balance penalty & $\eta$ & 0.05 & & & Ionescu (2011) \\
\hline Loan duration & $t_{\max }$ & 10 & & & Statutory \\
\hline Retention probability & $\pi$ & $0.554^{1 / 5}$ & & & $55.4 \%$ completion rate \\
\hline Earnings shocks & $\left(\rho, \sigma_{z}\right)$ & $(0.952,0.168)$ & & & Storesletten et al. (2004) \\
\hline Age-earnings profile & $\mu_{j}$ & Cubic & & & Storesletten et al. (2004) \\
\hline College premium & $\{\lambda\}$ & Table 4 & & & Autor et al. (2008) \\
\hline Non-tuition costs & $\{\phi\}$ & Table 4 & & & IPEDS \\
\hline Student loan rate & $\{i\}$ & Table 4 & & & Statutory \\
\hline Annual loan limits & $\left\{\bar{b}_{j}^{s}, \bar{b}_{j}^{u}, \bar{b}_{j}\right\}$ & Table 10 & & & Statutory \\
\hline Aggregate loan limits & $\left\{\bar{l}^{s}, \bar{l}^{u}, \bar{l}\right\}$ & Tables 4/10 & & & Statutory \\
\hline Custodial costs & $\left\{F, C^{2}\right\}$ & Table 2 & & & IPEDS regression \\
\hline Endowment flow & $\{E\}$ & Table 4 & & & IPEDS \\
\hline Grant aid & $\{\bar{\zeta}\}$ & Table 4 & & & IPEDS \\
\hline \multicolumn{6}{|c|}{ Calibration: Jointly Determined Parameters } \\
\hline Earnings normalization & $\nu$ & -1.25 & 31385 & 31352 & Mean earnings \\
\hline Parental transfers & $\xi$ & 0.208 & 5788 & 6100 & Mean net tuition \\
\hline Garnishment rate & $\gamma$ & 0.158 & 0.176 & 0.169 & Two-year default rate \\
\hline Ability input to quality & $\chi_{\theta}$ & 0.252 & 0.295 & 0.316 & Corr(p. income,enroll) \\
\hline College quality loading & $\chi_{q}$ & 2.68 & 0.379 & 0.325 & Enrollment rate \\
\hline Grant progressivity & $\hat{\zeta^{q}}$ & 1.85 & 0.027 & 0.021 & Average grant size \\
\hline Preference shock size & $\alpha$ & 290 & 0.357 & 0.427 & Percent with loans \\
\hline
\end{tabular}

Note: $\{x\}$ means $x$ has a transition path given in Table 4; $\$ x_{y y y y}$ means $\$ x$, measured nominally in yyyy dollars, converted to model units.

\footnotetext{
${ }^{21} \mathrm{An}$ exception is the correlation between parental income and enrollment, which we take from NLSY97.
} 


\begin{tabular}{|c|c|c|c|c|c|c|c|}
\hline year & $\overline{\lambda \lambda}$ & $i$ & $\overline{\bar{\phi}}$ & $\overline{\bar{\zeta}}$ & $\overline{\bar{l}^{s}}$ & $\overline{\bar{l}}^{u}$ & $\overline{\bar{l}}$ \\
\hline $1987^{*}$ & 0.46 & 4.7 & 3072 & 488 & 12500 & 0 & 12500 \\
\hline 1988 & 0.52 & 4.9 & 3253 & 462 & 17250 & 0 & 17250 \\
\hline 1989 & 0.53 & 4.4 & 3411 & 495 & 17250 & 0 & 17250 \\
\hline 1990 & 0.54 & 3.9 & 3593 & 683 & 17250 & 0 & 17250 \\
\hline 1991 & 0.55 & 5.2 & 3852 & 606 & 17250 & 0 & 17250 \\
\hline 1992 & 0.57 & 5.9 & 4006 & 804 & 23000 & 0 & 23000 \\
\hline 1993 & 0.58 & 5.5 & 4177 & 757 & 23000 & 23000 & 23000 \\
\hline 1994 & 0.59 & 6.0 & 4337 & 842 & 23000 & 31510 & 31510 \\
\hline 1995 & 0.59 & 6.1 & 4544 & 893 & 23000 & 31510 & 31510 \\
\hline 1996 & 0.60 & 5.8 & 4722 & 941 & 23000 & 31510 & 31510 \\
\hline 1997 & 0.61 & 6.4 & 4927 & 1372 & 23000 & 31510 & 31510 \\
\hline 1998 & 0.62 & 6.9 & 5166 & 1238 & 23000 & 31510 & 31510 \\
\hline 1999 & 0.62 & 6.1 & 5309 & 1245 & 23000 & 31510 & 31510 \\
\hline 2000 & 0.63 & 5.4 & 5551 & 1237 & 23000 & 31510 & 31510 \\
\hline 2001 & 0.64 & 4.3 & 5853 & 1329 & 23000 & 31510 & 31510 \\
\hline 2002 & 0.64 & 3.9 & 6131 & 1212 & 23000 & 31510 & 31510 \\
\hline 2003 & 0.65 & 2.3 & 6477 & 1396 & 23000 & 31510 & 31510 \\
\hline 2004 & 0.65 & 1.8 & 6804 & 1236 & 23000 & 31510 & 31510 \\
\hline 2005 & 0.65 & 2.4 & 7173 & 1455 & 23000 & 31510 & 31510 \\
\hline 2006 & 0.66 & 4.1 & 7540 & 1344 & 23000 & 31510 & 31510 \\
\hline 2007 & 0.66 & 4.0 & 7909 & 1305 & 23000 & 31510 & 31510 \\
\hline 2008 & 0.66 & 0.7 & 8364 & 1361 & 23000 & 40805 & 40805 \\
\hline 2009 & 0.66 & 4.1 & 8722 & 1357 & 23000 & 40805 & 40805 \\
\hline 2010 & 0.66 & 3.0 & 9129 & 1779 & 23000 & 40805 & 40805 \\
\hline
\end{tabular}

Note: Except for $\zeta$, all dollar values are nominal but converted to real in the computation. ${ }^{a}$ The "1987" borrowing limits correspond to the limits in place from 1981 to 1986. The "1987" college premium corresponds to the average from 1981 to $1987 .{ }^{b}$ The interest rates here correspond to five-year averages. See Appendix B for details. The notation $l^{u}\left(l^{u}=0\right.$ prior to 1993 and then $l^{u}=\bar{l}$ afterward) represents the aggregate unsubsidized loan limit.

Table 4: Transition Parameter Summary 


\subsection{Model Fit}

Table 5 presents key higher education statistics from the model and the data. The calibration

of the initial steady state directly targets the first set of statistics from 1987, while the remaining statistics act as an informal test of the model. Note that, while the calibration matches mean earnings, net tuition, and the two-year default rate from 1987 quite well, the model generates too little enrollment and too many students with loans.

We pinpoint two sources for these shortcomings. First, the presence of only one college in the model generates too much market power, which results in a small calibrated value for the parental transfers parameter $\xi$ in order to still match average net tuition. Thus, students rely more on borrowing. Second, by omitting ability terms in the post-college earnings process, we implicitly attribute the entire college premium to the sheepskin effect of a diploma (as opposed to selection effects). This exaggerated sheepskin effect generates a larger surplus from attending college, which the college partially captures through higher tuition.

Despite the presence of too many student borrowers, the model actually generates smaller average loans than in the data- $\$ 4,700$ vs. $\$ 7,100$. Lastly, the model nearly matches investment per student of $\$ 20,300$ in 1987 and the ratio of assets to income of about 3 . The matching of the asset-to-income ratio reflects the fact that our model of households is, at its core, a standard incomplete markets life-cycle model.

\section{Results}

Now we present the main results. First, we compare the model's initial and terminal steady states to the data from 1987 and 2010. Next, we evaluate the transition path of the model in light of the time series data. Lastly, we undertake a number of counterfactual experiments to quantify the explanatory power of each theory about the rise in college tuition.

\subsection{Steady State Comparisons}

\subsubsection{Tuition}

Of central importance, the model generates a 106\% increase in average net tuition-from approximately $\$ 6,100$ to $\$ 12,600$ - between the initial and terminal steady states. This jump compares to a $78 \%$ increase in the data. To illustrate how tuition changes, figure 4 plots slices of the tuition function and figure 12 in appendix $\mathrm{C}$ plots the entire function.

In both steady states, tuition does not move monotonically with income. Instead, tuition in the initial steady state first increases with parental income before it starts to decline at 
Equilibrium tuition for select ability levels

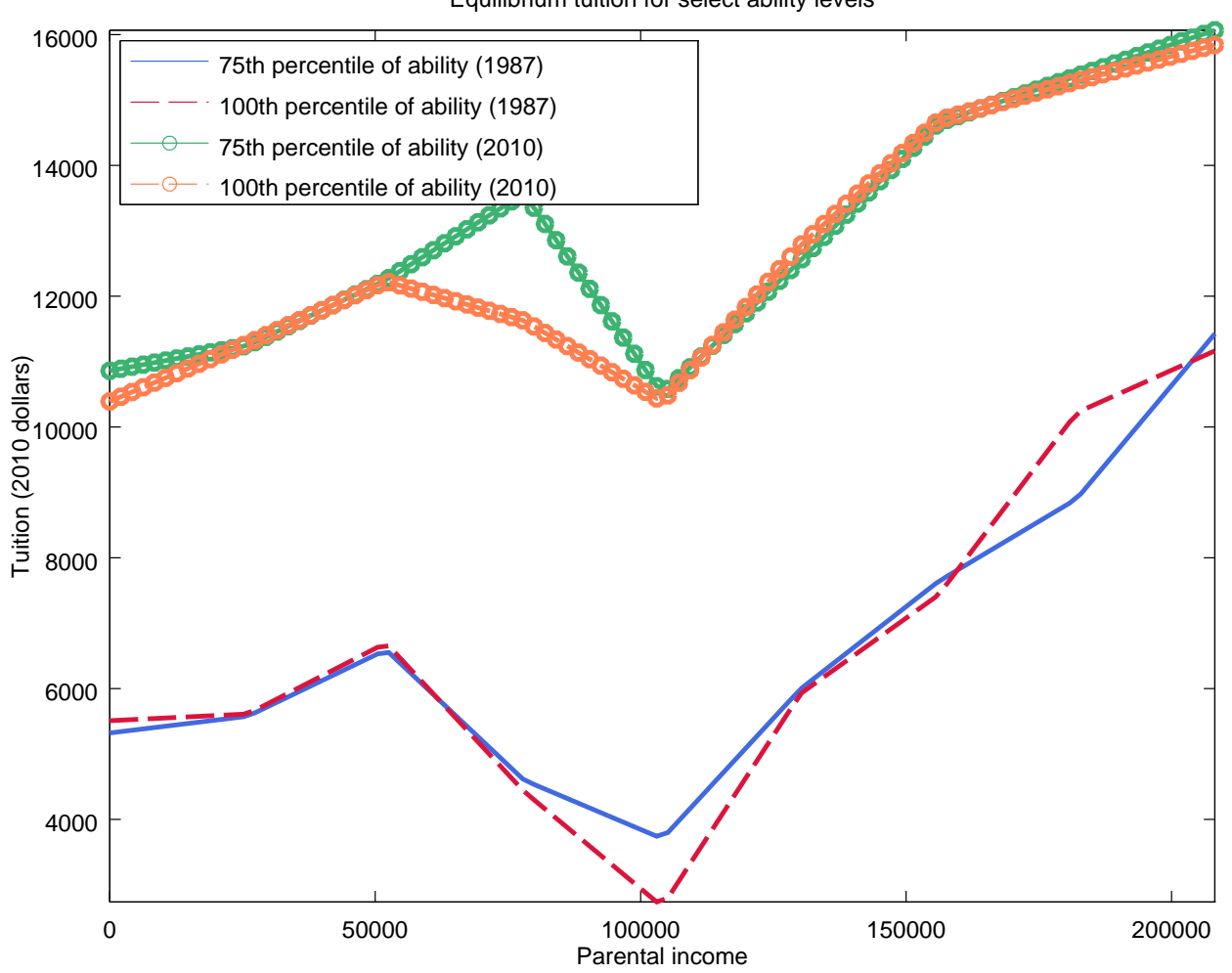

Figure 4: Slices of the Tuition Function 


\begin{tabular}{|c|c|c|c|c|}
\hline & $\begin{array}{c}\text { Model } \\
1987\end{array}$ & $\begin{array}{l}\text { Data } \\
1987\end{array}$ & $\begin{array}{c}\text { Model } \\
\text { Final SS }\end{array}$ & $\begin{array}{l}\text { Data } \\
2010\end{array}$ \\
\hline \multicolumn{5}{|l|}{ Statistics Targeted in 1987} \\
\hline Mean earnings ${ }^{z}$ & $\$ 31352$ & $\$ 31385^{*}$ & $\$ 36013$ & $\$ 36200$ \\
\hline Mean net tuition ${ }^{z}$ & $\$ 6100$ & $\$ 5788^{*}$ & $\$ 12559$ & $\$ 10293$ \\
\hline Two-year default rate ${ }^{a}$ & 0.169 & $0.176^{*}$ & 0.167 & 0.091 \\
\hline Enrollment rate ${ }^{b}$ & 0.325 & $0.379 *$ & 0.483 & 0.414 \\
\hline Graduation rate $^{c}$ & 0.554 & $0.554^{*}$ & 0.554 & 0.594 \\
\hline Attainment rate $(\operatorname{grad} \times \text { enroll })^{z}$ & 0.180 & $0.210^{*}$ & 0.267 & 0.246 \\
\hline Percent taking out loans ${ }^{e f}$ & 42.7 & $35.7^{*}$ & 100.0 & 52.9 \\
\hline Corr(parental income,enrollment) & 0.316 & - & 0.276 & $0.295^{*}$ \\
\hline \multicolumn{5}{|l|}{ Untargeted Statistics } \\
\hline Investment per student ${ }^{z}$ & $\$ 21550$ & $\$ 20251$ & $\$ 26837$ & $\$ 23750$ \\
\hline Average $\mathrm{EFC}^{\operatorname{def} z}$ & $\$ 19871$ & $\$ 16270$ & $\$ 16674$ & $\$ 13042$ \\
\hline Average annual loan size for recipients ${ }^{d e f z}$ & $\$ 4663$ & $\$ 7144$ & $\$ 6873$ & $\$ 8414$ \\
\hline Total assets / total income ${ }^{d g z}$ & 3.05 & 2.94 & 3.08 & 3.06 \\
\hline Student loan volume / total income ${ }^{d h z}$ & 0.010 & - & 0.047 & 0.050 \\
\hline Newly defaulted / non-defaulted loans ${ }^{h z}$ & 0.046 & - & 0.054 & 0.019 \\
\hline Newly defaulted / good standing borrowers ${ }^{h z}$ & 0.028 & - & 0.046 & 0.032 \\
\hline Pop with loans / age $18+$ pop $^{h i z}$ & 0.032 & - & 0.120 & 0.146 \\
\hline Ability of college graduates ${ }^{z}$ & 0.764 & - & 0.735 & 0.716 \\
\hline Corr(ability,enrollment) & 0.632 & - & 0.782 & 0.522 \\
\hline Non-garnishment payments / total income & 0.001 & - & 0.005 & - \\
\hline Garnishments / total income & 0.000 & - & 0.001 & - \\
\hline
\end{tabular}

*Targeted. Note: Unknown values are marked with "-".

Sources: ${ }^{a}$ stu (2015); ${ }^{b}$ nce (2015a); ${ }^{c}$ nce (2015b); ${ }^{d}$ FRE; ${ }^{e}$ Tables 2 and 7 in Wei et al. (2004); ${ }^{f}$ Tables 2.1-C and 3.3 Bersudskaya and Wei (2011); ${ }^{g}$ BEA; ${ }^{h}$ fed; ${ }^{i}$ Howden and Meyer (2011); and 'zauthors' calculations.

Table 5: Steady State Statistics 
income levels between $\$ 50,000$ and $\$ 100,000$ as financial aid eligibility tightens and grants decline. After $\$ 100,000$, tuition resumes its ascent as student ability to pay increases. The tuition curves shift up noticeably between the two steady states, though not in a parallel fashion. In particular, the region of declining tuition compresses to the range between $\$ 75,000$ and $\$ 100,000$, which is largely due to the expansion in aid between 1987 and 2010 .

Comparatively, the college engages in more modest price discrimination by academic ability than by parental income. ${ }^{22}$ Inspection of the 100th percentile and 75 th curves in 1987 reveals that tuition never differs by more than $\$ 700$ between moderate and high ability students. By 2000, the largest tuition difference between the 75th and 100th percentiles of the ability distribution rises to $\$ 2,000$.

When weighing whether to offer tuition discounts to high ability students, colleges face the trade-off between a higher ability student body and the need for resources to fund qualityenhancing investment expenditures. In our calibration, the latter effect dominates. The data provides supporting evidence. For instance, table 5, which presents selected statistics from the data and the initial and terminal steady states, shows that investment in the model increases by $25 \%$ between the two steady states. This increase approximates well the untargeted $17 \%$ rise in the data. While we lack data on student ability in 1987, the model's mean college graduate ability of 0.735 in 2010 closely matches the untargeted 0.716 from the data.

\subsubsection{Enrollment}

Figure 5 reveals how the enrollment patterns change between the steady states. Recall that the calibration targets the correlation between parental income and enrollment, and observe that average student ability aligns closely with the data in table 5 . However, figure 5 unveils a striking polarization of enrollment by income in the initial steady state. Specifically, middleincome students find themselves priced out of college, enrolling at a rate of less than $50 \%$.

As shown in equation 14, colleges set tuition by charging each student their type-specific effective marginal cost $E M C\left(s_{Y}\right)$ plus a markup that reflects the student's willingness to pay. Given that effective marginal cost only depends on the ability component $x\left(s_{Y}\right)$ of each student's type, all tuition variation within ability types derives from the impact of parental income and access to financial aid on student willingness to pay. ${ }^{23}$ Furthermore, in the absence of preference shocks (the limiting case as $\alpha \rightarrow \infty$ ), colleges first only admit

\footnotetext{
${ }^{22}$ In fact, theoretically, tuition should be monotonically decreasing in ability. However, due to computational cost, we have parametrized the tuition function more flexibly in the income dimension to account for more variation there. See appendix $\mathrm{C}$ for computation details.

${ }^{23}$ Replicated here: $T\left(s_{Y}\right)+\underbrace{\frac{\mathbb{P}\left(\operatorname{enroll} \mid s_{Y} ; T(\cdot), q\right)}{\partial \mathbb{P}\left(\operatorname{enroll} \mid s_{Y} ; T(\cdot), q\right) / \partial T}}_{(\partial \log \mathbb{P} / \partial T)^{-1}}=\underbrace{C^{\prime}(N)+I+\frac{q_{\theta}}{q_{I}}(\theta-x)}_{E M C\left(s_{Y}\right)}$
} 


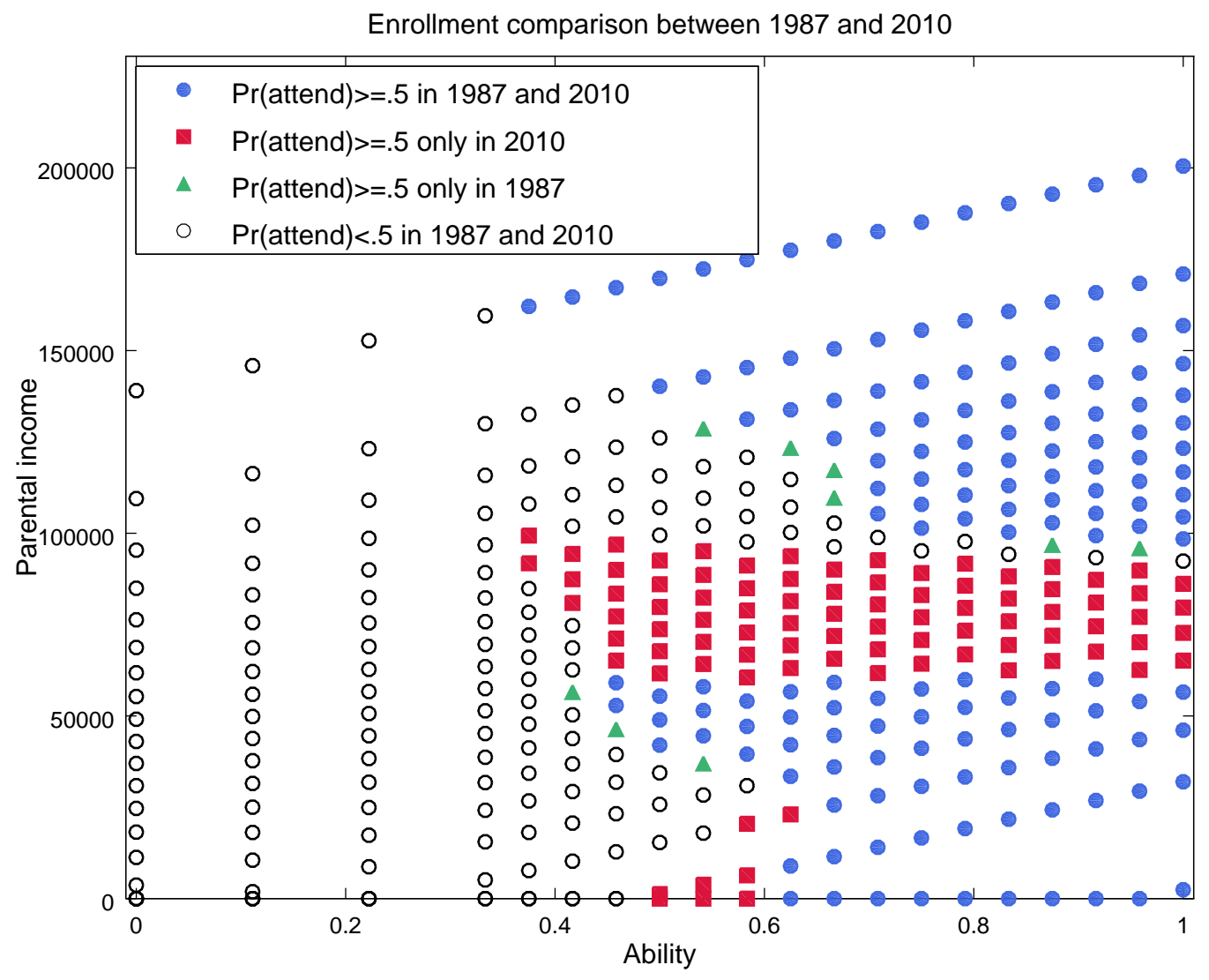

Figure 5: Attendance 
students that have a willingness to pay that exceeds their effective marginal cost, and then they proceed to charge tuition that extracts the entire surplus.

High-income students have a high willingness to pay because of parental transfers, while low-income students, despite lacking parental resources, have a high willingness to pay because of access to financial aid. Middle-income students find both of these avenues closed, in large part because each $\$ 1$ increase in parental income reduces access to subsidized borrowing by $\$ 1$ but only delivers $\xi<1$ dollars of additional resources to the student. Consequently, these students cannot afford to pay the full net tuition directly and also lack eligibility for subsidized loan borrowing, which represents the only form of student loans accessible in 1987. The college responds to the higher demand elasticity of these students by reducing their tuition, but the decrease does not prove sufficient to prevent low enrollment of middle-income students in the initial steady state.

By 2010, the introduction of unsubsidized loans and repeated expansions in grants and subsidized borrowing induces middle-income students to flood into higher education. These innovations partly explain the increase in enrollment from $33 \%$ to $48 \%$ across steady states, as reported in table 5. The data show a more subdued rise from $38 \%$ to $41 \%$.

\subsubsection{Borrowing and Default}

As we just explained, the enrollment surge between the initial and terminal steady states comes primarily from high-ability, middle-income youths who benefit from the introduction of unsubsidized loans and expansion of subsidized aid. In fact, in the terminal steady state, every single college student participates at least minimally in student borrowing (recall that $\beta=$ 0.96 and the loan interest rate in 2010 is 3\%, which makes student loans an attractive form of borrowing). Empirically, the percentage of students with loans increases more moderately from $35.7 \%$ to $52.9 \%$. That said, although the model greatly overestimates participation in the student loan program, it generates an average loan size of only $\$ 6,900$ compared to $\$ 8,400$ in the 2010 data.

The model also yields a modest decline in the student loan default rate from $17.1 \%$ to $16.7 \%$. The data, by contrast, show a much larger fall from $17.6 \%$ to $9.1 \%$. This discrepancy largely comes from the fact that legal changes between 1987 and 2010 increased the cost of student loan default, whereas we abstract from such changes in the model.

\subsubsection{Life-Cycle Behavior}

Figure 6 displays how loans, consumption, and default rates vary over the life-cycle for differing levels of college attainment (measured as the number of completed years of college). 
For each group, average outstanding loans shrink over time and virtually disappear by age 45. Considering the 10 year loan duration, this later than expected age owes much to a wave of student loan defaults that occurs prior to age 30. Given that we abstract from legal changes between 1987 and 2010 that increased the penalties of default, the model generates too much default and too much willingness of students to borrow in the first place. In turn, the upwardly-biased willingness to borrow likely distorts equilibrium tuition.

Consumption exhibits the familiar hump-shaped profile seen frequently in life-cycle models. In particular, the earnings process follows a hump-shaped profile, and although households prefer to smooth consumption, borrowing constraints prevent them from doing so completely. Interestingly, the effects of debt overhang are clearly visible: Despite a large increase in the return to a year of schooling, consumption barely changes from 1987 to 2010 for young workers who completed two years of college.
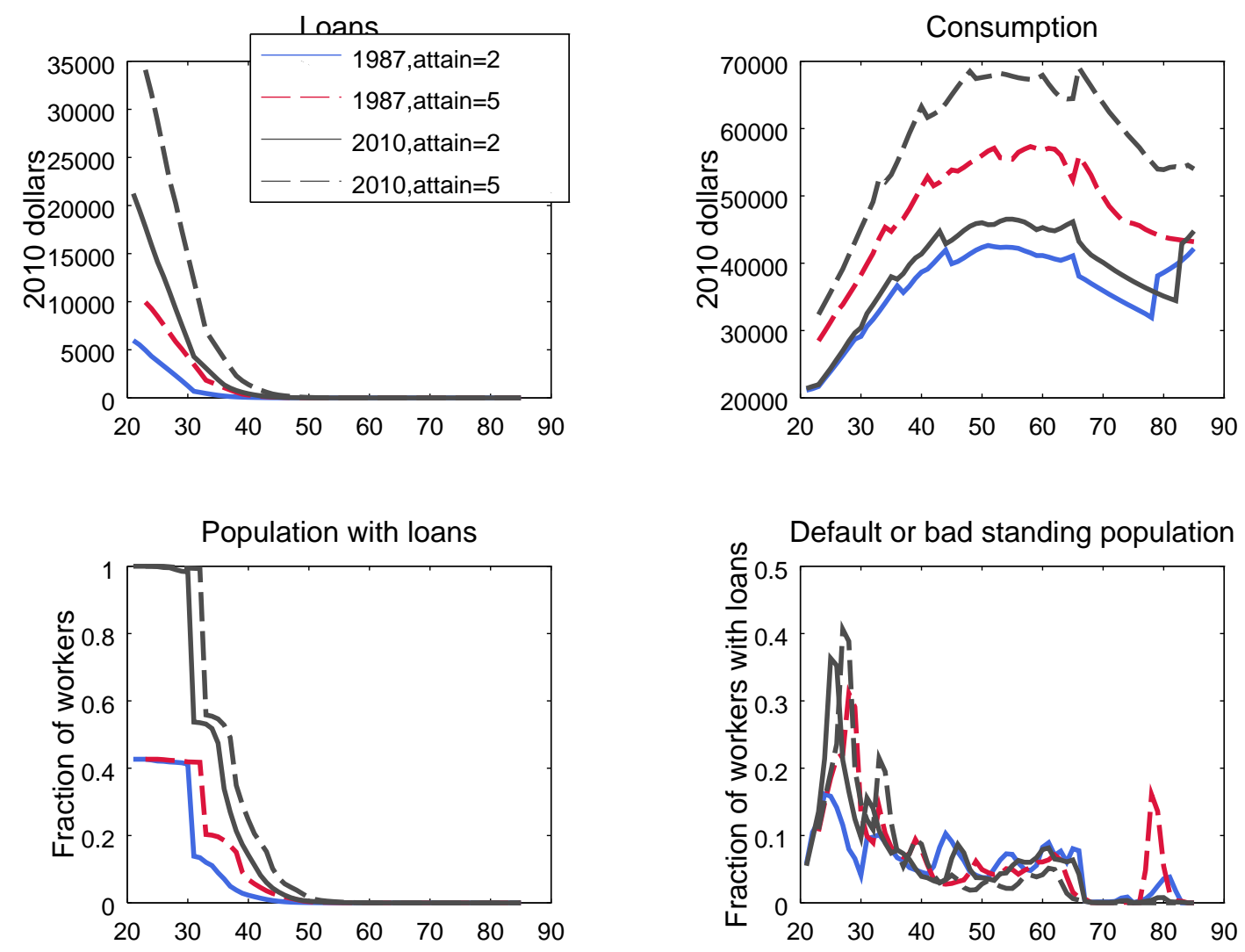

Figure 6: Life-Cycle Profiles 


\subsection{Transition Path Dynamics}

Given that we have constructed a rich time series of borrowing limits, the college premium, college endowments, and measured custodial costs, we can gain further insights by analyzing the entire transition path of the model. Figure 7 plots the path of net tuition, enrollment, and investment expenditures in both the model and the data.

While investment per student in the model lines up well with the data, equilibrium tuition follows a different trajectory than net tuition in the data. In particular, although the model generates an overall increase in tuition similar to that in the data, equilibrium tuition rises rapidly between 1993 and 1997 before stagnating, while empirical net tuition increases gradually during the entire time period. As the next section will make clear, the expansion in financial aid following the re-authorization of the Higher Education Act in 1992 drives a significant fraction of the rise in tuition. Although the college premium increased from 0.46 to 0.58 log points between 1987 and 1993, many middle-income households lacked the resources or borrowing capacity to take advantage by enrolling in college. The 1992 reform significantly loosened credit constraints by introducing unsubsidized loans.

We can only speculate as to why net tuition in the data does not accelerate in 1993. To the extent that political concerns partially govern the setting of tuition, colleges may prefer to spread out tuition increases over longer time horizons rather than announce rapid escalations. Alternatively, students may not have accurately forecast the persistent rise in the college premium, whereas our solution method assumes perfect foresight. Lastly, colleges may engage in some form of tacit collusion that takes time to implement, a feature our model cannot capture by virtue of our representative college assumption.

The overly rapid increase in tuition may also explain the divergent pattern in enrollments between 1993 and 1998. In particular, the data enrollments increase steadily whereas model enrollments fall substantially. Had the college in the model "smoothed" tuition over this period, enrollments might not have fallen so sharply.

\subsection{Assessing the Theories of Tuition Inflation}

Now we turn to our main question of assessing why net tuition has almost doubled since 1987. Notably, our model successfully replicates this rise without using it as a calibration target. We proceed to quantify the role of the following factors in this tuition rise: i) changes in custodial costs and non-tuition sources of revenue, such as endowments and state support (supply shocks), ii) changes in student loan borrowing limits, interest rates, grant aid, and non-tuition costs, such as room and board (demand shocks), and iii) macroeconomic forces, namely, the rise in the college wage premium. 


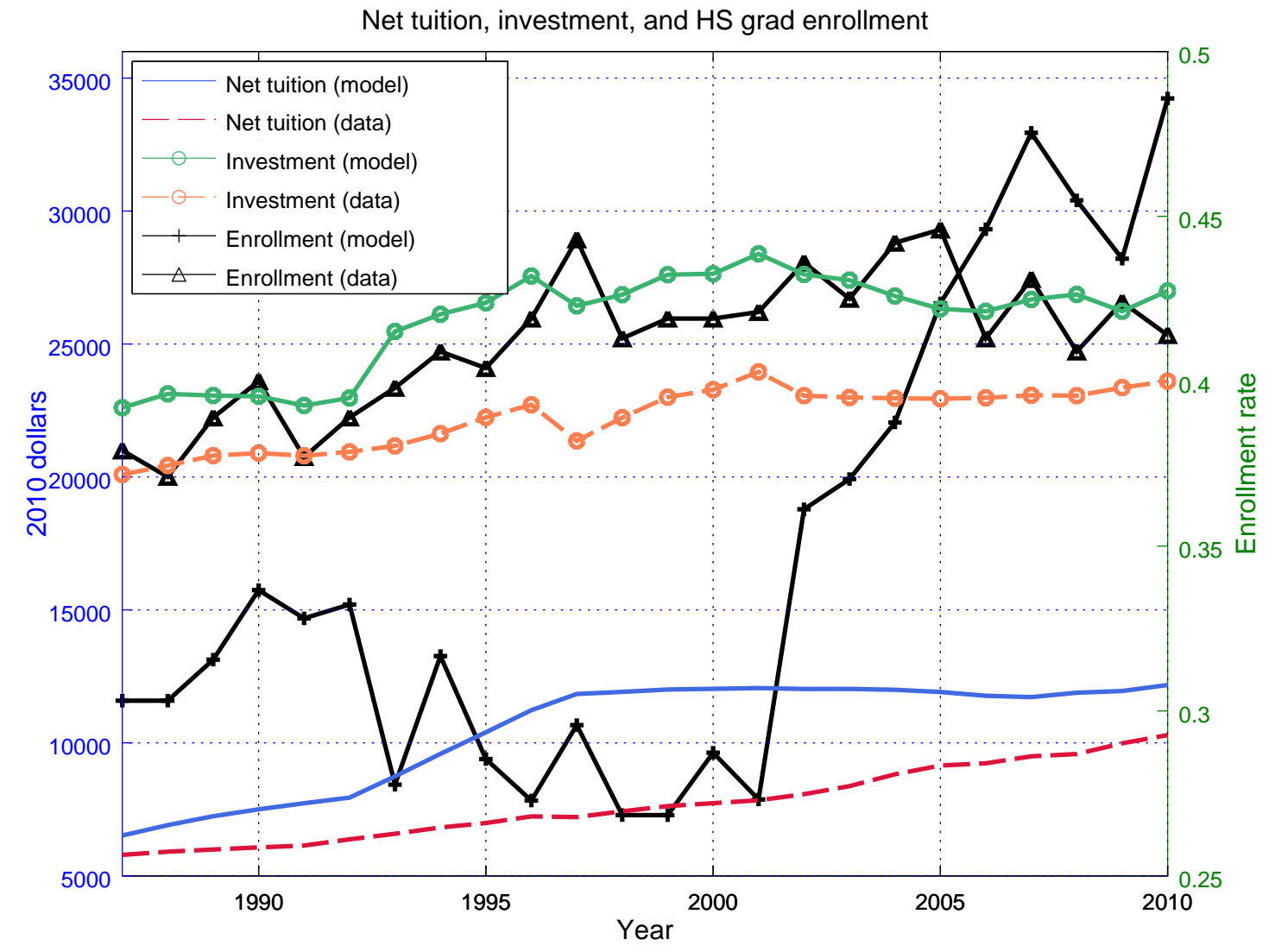

Figure 7: Comparison of Model and Data Over the Transition 
We undertake the tuition decomposition from two different angles. First, we progressively solve the model by implementing only one of the broad categories of shocks at a time, which answers the question "How much would tuition have gone up if only X had occurred?" Then we sequentially shut down the supply shocks, demand shocks, and the college wage premium one at a time. This approach allows us to answer the question "How much would tuition have gone up if X had not occurred?" Lastly, we break down the effect of the individual factors that constitute our categorizations. In all the experiments, we solve for the tax rate that ensures a balanced budget for the government.

\subsubsection{Demand Shocks: The Bennett Hypothesis}

Table 6 summarizes the decomposition through some key statistics. With all factors present, net tuition increases from $\$ 6,100$ to $\$ 12,559$. As column 4 demonstrates, the demand shockswhich consist mostly of changes in financial aid - account for the lion's share of the higher tuition. Specifically, with demand shocks alone, equilibrium tuition rises by $102 \%$, almost fully matching the $106 \%$ from the benchmark. By contrast, with all factors present except the demand shocks (column 7 ), net tuition only rises by $16 \%$.

These results accord strongly with the Bennett hypothesis, which asserts that colleges respond to expansions of financial aid by increasing tuition. In fact, the tuition response completely crowds out any additional enrollment that the financial aid expansion would otherwise induce, resulting instead in an enrollment decline from $33 \%$ to $27 \%$ in the new equilibrium with only demand shocks. Furthermore, the students who do enroll take out $\$ 6,876$ in loans compared to $\$ 4,663$ in the initial steady state. The college, in turn, uses these funds to finance an increase of investment expenditures from $\$ 21,550$ to $\$ 27,338$ and to enhance the quality of the student body. In particular, the average ability of graduates increases by 4 percentage points (pp). Lastly, the model predicts that demand shocks in isolation generate a surge in the default rate from $17 \%$ to $32 \%$. Essentially, demand shocks lead to higher college costs and more debt, and in the absence of higher labor market returns, more loan default inevitably occurs.

As a caveat, we view this measured effect as an upper bound for the Bennett hypothesis. Given our assumption of a non-competitive representative college, only the presence of the unobservable preference shocks impedes the college from extracting the entire consumer surplus from its student body. Table 6 illustrates this market power in the remarkably small variation in ex-ante utility across the decompositions (the variation is less than $1.6 \%$ in consumption equivalent terms). With more colleges, competition would act as a buffer against unbridled rent extraction and different pricing patterns would emerge. Given the difficulty of solving for equilibrium with multiple colleges, we leave it for future research. 


\begin{tabular}{|c|c|c|c|c|c|c|c|c|}
\hline Statistic & 1987 & \multicolumn{6}{|c|}{ Experiment } & 2010 \\
\hline College costs & & & & $*$ & & $*$ & * & $*$ \\
\hline College endowment & & & & $*$ & & $*$ & * & * \\
\hline Borrowing limits & & & $*$ & & $*$ & & $*$ & $*$ \\
\hline Interest rates & & & $*$ & & $*$ & & * & $*$ \\
\hline Non-tuition cost & & & $*$ & & $*$ & & $*$ & $*$ \\
\hline Grants & & & $*$ & & $*$ & & $*$ & $*$ \\
\hline College premium & & * & & & $*$ & $*$ & & $*$ \\
\hline Mean net tuition & $\$ 6100$ & $\$ 7583$ & $\$ 12345$ & $\$ 5762$ & $\$ 13525$ & $\$ 7061$ & $\$ 11415$ & $\$ 12559$ \\
\hline Std. net tuition & $\$ 1493$ & $\$ 1402$ & $\$ 1325$ & $\$ 1445$ & $\$ 1369$ & $\$ 1343$ & $\$ 1302$ & $\$ 1245$ \\
\hline Enrollment rate & 0.33 & 0.29 & 0.27 & 0.48 & 0.30 & 0.48 & 0.49 & 0.48 \\
\hline Two-year default rate & 0.17 & 0.15 & 0.32 & 0.17 & 0.17 & 0.15 & 0.32 & 0.17 \\
\hline Mean loan (recipients) & $\$ 4663$ & $\$ 4710$ & $\$ 6876$ & $\$ 4658$ & $\$ 6873$ & $\$ 4627$ & $\$ 6877$ & $\$ 6873$ \\
\hline Pct. taking out loans & 42.7 & 50.5 & 100.00 & 51.1 & 100.00 & 55.7 & 100.00 & 100.00 \\
\hline Mean earnings & $\$ 31352$ & $\$ 32899$ & $\$ 30804$ & $\$ 32960$ & $\$ 32918$ & $\$ 35902$ & $\$ 33077$ & $\$ 36013$ \\
\hline Corr(p.income,enroll) & 0.32 & 0.25 & 0.27 & 0.18 & 0.23 & 0.16 & 0.27 & 0.28 \\
\hline Corr(ability,enroll) & 0.63 & 0.63 & 0.63 & 0.53 & 0.65 & 0.59 & 0.75 & 0.78 \\
\hline Ability of graduates & 0.76 & 0.78 & 0.80 & 0.66 & 0.79 & 0.68 & 0.72 & 0.74 \\
\hline Investment & $\$ 21550$ & $\$ 22793$ & $\$ 27338$ & $\$ 20034$ & $\$ 28744$ & $\$ 21288$ & $\$ 25772$ & $\$ 26837$ \\
\hline Average EFC & $\$ 19871$ & $\$ 19024$ & $\$ 18628$ & $\$ 16471$ & $\$ 17527$ & $\$ 15923$ & $\$ 16674$ & $\$ 16674$ \\
\hline Ex-ante utility & -40.98 & -40.99 & -40.97 & -40.78 & -40.83 & -40.70 & -40.71 & -40.36 \\
\hline
\end{tabular}

Table 6: Experiments

\subsubsection{Macroeconomic Forces: The Rising College Wage Premium}

The rise in the college wage premium also contributes to higher tuition, albeit more modestly. If only the college wage premium changed between 1987 and 2010, the model predicts that net tuition would have gone up by $24 \%$. In its absence, but with all other shocks present, tuition would have gone up by $87 \%$. Interestingly, the rise in the college wage premium does not appear to generate any increase in enrollment. Instead, the average ability of the student body shifts upward by 2 pp, and the overall enrollment actually falls from $33 \%$ to $29 \%$. In part, limitations in borrowing capacity acted as a binding constraint for (mostly middleincome) students in 1987, and absent any increase in financial aid, labor market changes alone could not drive up enrollment.

\subsubsection{Supply Shocks: Cost Disease and Fluctuations in Non-Tuition Revenue}

Lastly, our results cast considerable doubt on the role of Baumol's cost disease and fluctuations in non-tuition revenue (such as state funding support for higher education) as explanations for higher tuition. In fact, not only do we find that these factors do not lead to large increases in tuition, but our results show that tuition falls in response to supply shocks alone. Specifically, when we feed in the empirical estimates for the changes in custodial costs and college endowments (which consist of all non-tuition revenue sources) but leave all other 


\begin{tabular}{|c|c|c|c|c|c|c|c|c|}
\hline Statistic & & & & Experime & & & & 2010 \\
\hline College costs & & * & * & * & * & $*$ & * & $*$ \\
\hline College endowment & $*$ & & $*$ & * & * & $*$ & * & * \\
\hline Borrowing limits & $*$ & * & & $*$ & $*$ & $*$ & $*$ & $*$ \\
\hline Interest rates & $*$ & $*$ & $*$ & & $*$ & $*$ & $*$ & $*$ \\
\hline Non-tuition cost & * & * & $*$ & * & & $*$ & $*$ & $*$ \\
\hline Grants & * & * & $*$ & $*$ & $*$ & & $*$ & $*$ \\
\hline College premium & $*$ & $*$ & $*$ & $*$ & $*$ & $*$ & & $*$ \\
\hline Mean net tuition & $\$ 13678$ & $\$ 12797$ & $\$ 9949$ & $\$ 12433$ & $\$ 12591$ & $\$ 11454$ & $\$ 11415$ & $\$ 12559$ \\
\hline Std. net tuition & $\$ 1266$ & $\$ 1338$ & $\$ 1216$ & $\$ 1342$ & $\$ 1267$ & $\$ 1981$ & $\$ 1302$ & $\$ 1245$ \\
\hline Enrollment rate & 0.29 & 0.49 & 0.41 & 0.51 & 0.47 & 0.48 & 0.49 & 0.48 \\
\hline Two-year default rate & 0.17 & 0.17 & 0.07 & 0.19 & 0.17 & 0.17 & 0.32 & 0.17 \\
\hline Mean loan (recipients) & $\$ 6872$ & $\$ 6873$ & $\$ 4774$ & $\$ 6856$ & $\$ 6872$ & $\$ 6871$ & $\$ 6877$ & $\$ 6873$ \\
\hline Pct. taking out loans & 100.00 & 100.00 & 87.0 & 100.00 & 100.00 & 100.00 & 100.00 & 100.00 \\
\hline Mean earnings & $\$ 32812$ & $\$ 36140$ & $\$ 34786$ & $\$ 36389$ & $\$ 35875$ & $\$ 35897$ & $\$ 33077$ & $\$ 36013$ \\
\hline Corr(p.income,enroll) & 0.32 & 0.30 & -0.21 & 0.31 & 0.27 & 0.48 & 0.27 & 0.28 \\
\hline Corr(ability,enroll) & 0.65 & 0.75 & 0.37 & 0.76 & 0.73 & 0.80 & 0.75 & 0.78 \\
\hline Ability of graduates & 0.80 & 0.72 & 0.63 & 0.72 & 0.72 & 0.74 & 0.72 & 0.74 \\
\hline Investment & $\$ 29415$ & $\$ 26558$ & $\$ 23559$ & $\$ 26875$ & $\$ 26805$ & $\$ 25678$ & $\$ 25772$ & $\$ 26837$ \\
\hline Average EFC & $\$ 19206$ & $\$ 16746$ & $\$ 9637$ & $\$ 16702$ & $\$ 16898$ & $\$ 19578$ & $\$ 16674$ & $\$ 16674$ \\
\hline Ex-ante utility & -40.87 & -40.46 & -40.71 & -40.35 & -40.61 & -40.55 & -40.71 & -40.36 \\
\hline
\end{tabular}

Table 7: Experiments

parameters at their initial 1987 levels, equilibrium tuition decreases modestly from $\$ 6,100$ to $\$ 5,762$. Enrollment, by contrast, surges from $33 \%$ to $48 \%$. We discuss the reason shortly.

\subsubsection{Further Decomposing the Rise in Tuition}

At this point, we need to unpack the impact of changing custodial costs and changes in the college's endowment to understand why supply shocks act to lower tuition in the model. Table 7 shows what happens when we solve the model by taking turns shutting down exactly one of the factors that change between 1987 and 2010.

Comparing column 2 to the 2010 column, one sees that omitting the change in custodial costs causes tuition to rise by approximately $\$ 1,100$ more than it does in the baseline 2010 equilibrium. By contrast, shutting down the changes in the college's endowment (seen in column 3) increases tuition by $\$ 200$. In other words, despite the fact that we estimate an increase in custodial costs between 1987 and 2010, these higher costs reduce tuition.

Careful consideration of the college's objective function, budget constraint, and first order condition sheds some insight. In particular, recall that the first order condition of the college problem sets tuition equal to effective marginal cost, $E M C\left(s_{Y}\right)=C^{\prime}(N)+I+\frac{q_{\theta}}{q_{I}}(\theta-x)$, plus a markup based on the demand elasticity. Our regression estimates find that both the fixed cost and quadratic cost terms of $C$ increase between 1987 and 2010, so $C^{\prime}$ increases, 
which would increase tuition, all else equal. However, in equilibrium, the higher fixed cost causes the college to cut back significantly on investment $I$. Overall, we find that the latter effect dominates, causing $E M C$ and tuition to fall in response to the custodial cost increase.

A different way to understand this result recognizes that fixed costs largely drive the increase in college costs. The college cannot effectively offset this cost by raising revenue from the existing student body because it already engages in substantial rent extraction. Thus, the college must raise revenue from other sources and/or reduce costs. Because average ability and investment are complements in the quality production function, colleges cut investment and average ability in response to this budgetary pressure (see column 5 of table 6).

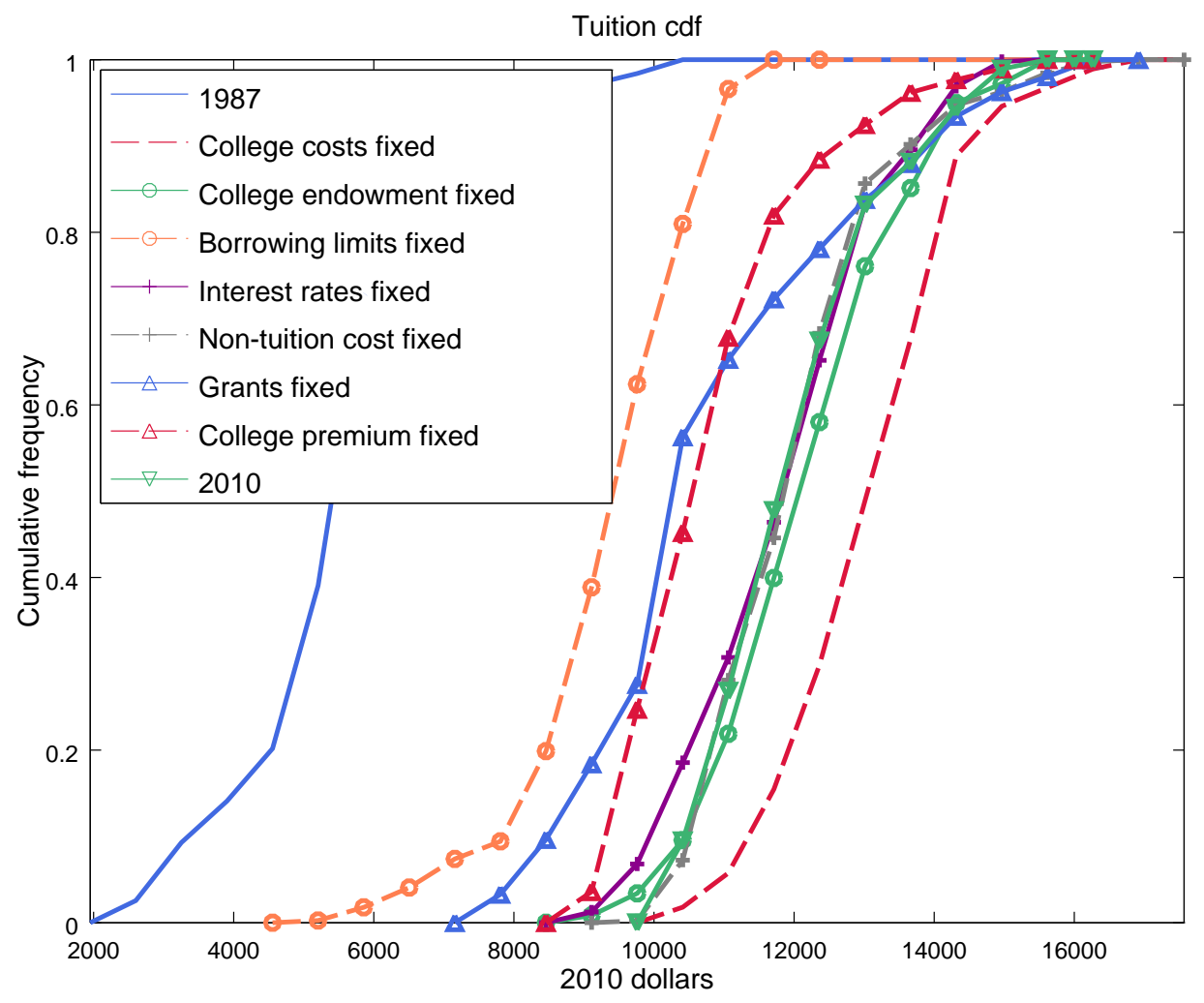

Figure 8: Tuition Cumulative Distribution Function

Also surprisingly, changes in college endowments show little effect on equilibrium tuition. However, inspection of figure 2 reveals that endowments per FTE only change by approximately $\$ 600$ between 1987 and 2010. Given that our model effectively lumps private and public colleges together, it appears that changes in state funding support and changes in other sources of non-tuition revenue largely offset each other. In future work, we plan to disaggregate the model along the public/private dimension.

While we have focused our attention on average net tuition, the model also has predictions 
for the entire distribution of net tuition. Figure 8 displays the distribution of net tuition for 1987, 2010, and the experiments listed in table 7. Some of the experiments have virtually no effect on tuition at any point of the distribution, namely, interest rates, non-tuition cost, and changes in the college endowment. Other changes, such as grants, have a large firstorder effect but have even larger effects at the bottom of the distribution. Table 7 provides corroborating evidence for these distributional consequences by listing the standard deviation of net tuition in each experiment. Notably, the increase in grants over the transition lowers the standard deviation of net tuition from $\$ 1,981$ to $\$ 1,245$.

\section{Conclusion}

Existing theories can fully explain the increase in net tuition between 1987 and 2010. Our model suggests demand-side theories have the most predictive power. In fact, our results show the Bennett hypothesis can fully account for the tuition increase on its own. We suspect that our model exaggerates the explanatory power of the demand-side theories as a result of the lack of competition faced by the college. We find that several compelling supplyside theories, such as Baumol's cost disease and changes in other college funding sources, have little quantitative impact and can even move in the wrong direction. To assess the robustness of our findings and to allow for more plausible welfare and policy analysis, we plan to incorporate heterogeneous colleges in future work.

\section{References}

Table 2-1, Current-Cost Net Stock of Private Fixed Assets, Equipment, Structures, and Intellectual Property Products by Type. Bureau of Economic Analysis, http://www . bea . gov. Accessed: 2015-06-18.

FRED data series (CPIAUCSL, GDP, LFWA64TTUSA647N, DHLCRG3Q086SBEA). Federal Reserve Economic Database, https://research.stlouisfed.org/fred2/. Accessed: 2015-06-18.

Federal student loan portfolio. https://studentaid.ed.gov/sa/about/data-center/ student/portfolio. Accessed: 2015-06-18.

Delta cost project documentation of IPEDS database and related products. http:// nces.ed.gov/ipeds/deltacostproject/download/DCP_History_Documentation.pdf, December 2011. Accessed: 2015-04-05. 
Table 302.10. Recent high school completers and their enrollment in 2-year and 4-year colleges, by sex: 1960 through 2013. National Center for Education Statistics, http://nces . ed.gov/programs/digest/d14/tables/dt14_302.10.asp, 2015a. Accessed: 2015-06-18.

Table 326.10. Graduation rate from first institution attended for first-time, full-time bachelor's degree- seeking students at 4-year postsecondary institutions, by race/ethnicity, time to completion, sex, control of institution, and acceptance rate: Selected cohort entry years, 1996 through 2007. National Center for Education Statistics, http://nces.ed. gov/programs/digest/d14/tables/dt14_326.10.asp, 2015b. Accessed: 2015-06-18.

Table 330.10. Average undergraduate tuition and fees and room and board rates charged for full-time students in degree-granting postsecondary institutions, by level and control of institution: 1963-64 through 2013-14. National Center for Education Statistics, http:// nces.ed.gov/programs/digest/d14/tables/dt14_330.10.asp, 2015c. Accessed: 201506-20.

National student loan two-year default rates. Federal Student Aid, https://www2.ed.gov/ offices/OSFAP/defaultmanagement/defaultrates.html, 2015. Accessed: 2015-06-18.

B. Abbott, G. Gallipoli, C. Meghir, and G. Violante. Education policy and intergenerational transfers in equilibrium. Mimeo, 2013.

R. J. Andrews, J. Li, and M. F. Lovenheim. Quantile treatment effects of college quality on earnings: Evidence from administrative data in texas. Mimeo, 2012.

R. B. Archibald and D. H. Feldman. Explaining increases in higher education costs. The Journal of Higher Education, 79(3):268-295, 2008.

K. Athreya and J. Eberly. The supply of college-educated workers: The roles of college premia, college costs, and risk. Mimeo, 2013.

D. H. Autor, L. F. Katz, and M. S. Kearney. Trends in U.S. wage inequality: Revising the revisionists. The Review of Economics and Statistics, 90(2):300-323, May 2008.

W. J. Baumol. Macroeconomics of unbalanced growth: The anatomy of urban crisis. The American Economic Review, 57(3):415-426, 1967.

W. J. Baumol and W. G. Bowen. Performing Arts: The Economic Dilemma; a Study of Problems Common to Theater, Opera, Music, and Dance. Twentieth Century Fund, 1966.

P. Belley and L. Lochner. The changing role of family income and ability in determining educational achievement. Journal of Human Capital, 1(1):37-89, 2007. 
W. J. Bennett. Our greedy colleges. The New York Times, February 18, 1987.

V. Bersudskaya and C. C. Wei. Trends in student financing of undergraduate education: Selected years 1995-96 to 2008-08. Report NCES 2011-218, National Center for Education Statistics, 2011.

H. R. Bowen. The Costs of Higher Education: How Much Do Colleges and Unversities Spend per Student and How Much Should They Spend. Jossey-Bass Publishers, San Francisco, CA, 1980.

D. Card and T. Lemieux. Can falling supply explain the rising return to college for younger men? Quarterly Journal of Economics, 116:705-746, 2001.

S. R. Cellini and C. Goldin. Does federal aid raise tuition? New evidence on for-profit colleges. American Economic Journal: Economic Policy, 6(4):174-206, 2014.

R. Chakrabarty, M. Mabutas, and B. Zafar. Soaring tuitions: Are public funding cuts to blame? http://www.http://libertystreeteconomics.newyorkfed.org/2012/09/ soaring-tuitions-are-public-funding-cuts-to-blame.html\#.VeDDrPlVhBc, 2012. Accessed: 2015-08-28.

S. Choy. Nontraditional undergraduates: Findings from the "Condition of Education, 2002". Report NCES-2002-012, National Center for Education Statistics, 2002.

C. T. Clotfelter. Buying the Best: Cost Escalation in Elite Higher Education. Princeton University Press, 1996.

A. F. Cunningham, J. V. Wellman, M. E. Clinedinst, J. P. Merisotis, and C. D. Carroll. Study of college costs and prices, 1988 - 89 to 1997 - 98, volume 1. Report NCES 2002157, National Center for Education Statistics, 2001a.

A. F. Cunningham, J. V. Wellman, M. E. Clinedinst, J. P. Merisotis, and C. D. Carroll. Study of college costs and prices, 1988 - 89 to 1997 - 98, volume 2: Commissioned papers. Report NCES 2002-157, National Center for Education Statistics, 2001b.

R. G. Ehrenberg. Tuition Rising: Why College Costs So Much. Harvard University Press, 2002.

D. Epple, R. Romano, and H. Sieg. Admission, tuition, and financial aid policies in the market for higher education. Econometrica, 74(4):885-928, 2006. 
D. Epple, R. Romano, S. Sarpca, and H. Sieg. The U.S. market for higher education: A general equilibrium analysis of state and private colleges and public funding policies. Mimeo, 2013.

I. Fillmore. Price discrimination and public policy in the u.s. college market. Mimeo, 2014.

A. B. Frederick, S. J. Schmidt, and L. S. Davis. Federal policies, state responses, and community college outcomes: Testing an augmented bennett hypothesis. Economics of Education Review, 31(6):908-917, 2012.

C. Fu. Equilibrium tuition, applications, admissions, and enrollment in the college market. Journal of Political Economy, Forthcoming, 2014.

C. Garriga and M. P. Keightley. A general equilibrium theory of college with education subsidies, in-school labor supply, and borrowing constraints. Mimeo, 2010.

C. Goldin and L. F. Katz. The race between education and technology: The evolution of u.s. educational wage differentials, 1890 to 2005. NBER Working Paper, 2007.

G. Gordon and S. Qiu. A divide and conquer algorithm for exploiting policy function monotonicity. CAEPR WP 2015-002, Indiana University, 2015.

D. E. Heller. The effects of tuition and state financial aid on public college enrollment. The Review of Higher Education, 23(1):65-89, 1999.

M. Hoekstra. The effect of attending the flagship state university on earnings. The Review of Economics and Statistics, 91(4):717-724, 2009.

L. M. Howden and J. A. Meyer. Age and Sex Composition: 2010, Table 1. United States Census Bureau, http://www.census.gov/prod/cen2010/briefs/c2010br-03. pdf, 2011. Accessed: 2015-06-18.

F. Ionescu. Risky human capital and alternative bankruptcy regimes for student loans. Journal of Human Capital, 5(2):153-206, 2011.

F. Ionescu and N. Simpson. Credit risk and default: Implications for higher education policies. Mimeo, 2015.

J. B. Jones and F. Yang. Skill-biased technological change and the cost of higher education. Journal of Labor Economics, Forthcoming, 2015.

L. F. Katz and K. M. Murphy. Changes in relative wages, 1963 - 87: Supply and demand factors. Quarterly Journal of Economics, 107:35-78, 1992. 
M. P. Keane and K. I. Wolpin. The effect of parental transfers and borrowing constraints on educational attainment. International Economic Review, 42(4):1051-1103, 2001.

R. K. Koshal and M. Koshal. State appropriation and higher education tuition: What is the relationship? Education Economics, 8(1), 2000.

L. J. Lochner and A. Monge-Naranjo. The nature of credit constraints and human capital. American Economic Review, 101(6):2487-2529, 2011.

B. T. Long. How do financial aid policies affect colleges? the institutional impact of the georgia hope scholarship. Journal of Human Resources, 39(4):1045-1066, 2004a.

B. T. Long. The impact of federal tax credits for higher education expenses. In C. M. Hoxby, editor, College Choices: The Economics of Where to Go, When to Go, and How to Pay for It, pages $101-168$. University of Chicago Press, 2004b.

B. T. Long. College tuition pricing and federal financial aid: Is there a connection? Technical report, Testimony before the U.S. Senate Committee on Finance, 2006.

D. O. Lucca, T. Nadauld, and K. Shen. Credit supply and the rise in college tuition: Evidence from expansion in federal student aid programs. Mimeo, 2015.

M. S. McPherson and M. O. Shapiro. Keeping College Affordable: Government and Educational Opportunity. Brookings Institution Press, 1991.

M. J. Rizzo and R. G. Ehrenberg. Resident and nonresident tuition and enrollment at flagship state universities. In C. M. Hoxby, editor, College Choices: The Economics of Where to Go, When to Go, and How to Pay for It, pages 303 - 353. University of Chicago Press, 2004.

L. D. Singell, Jr. and J. A. Stone. For whom the Pell tolls: The response of university tuition to federal grants-in-aid. Economics of Education Review, 26:285-295, 2007.

D. P. Smole. Federal student loans made under the Federal Family Education Loan program and the William D. Ford Federal Direct Loan program: Terms and conditions for borrowers. http://www. nasfaa.org/EntrancePDF . aspx?id=8378, 2012. Accessed: 2015-05-28.

K. Storesletten, C. Telmer, and A. Yaron. Cyclical dynamics in idiosyncratic labor market risk. Journal of Political Economy, 112(3):695-717, 2004. 
M. A. Titus, S. Simone, and A. Gupta. Investigating state appropriations and net tuition revenue for public higher education: A vector error correction modeling approach. Working paper, Institute for Higher Education Law and Governance Institute Monograph Series, 2010.

L. J. Turner. The road to Pell is paved with good intentions: The economic incidence of federal student grant aid. Mimeo, 2014.

N. Turner. Who benefits from student aid: The economic incidence of tax-based aid. Economics of Education Review, 31(4):463-481, 2012.

C. C. Wei, X. Li, L. Berkner, and C. D. Carroll. A decade of undergraduate student aid: 1989-90 to 1999-2000. Report NCES 2004-158, National Center for Education Statistics, 2004.

G. C. Winston. Subsidies, hierarchy, and peers: The awkward economics of higher education. The Journal of Economic Perspectives, 13(1):13-36, 1999.

M. Wolverton, W. H. Gmeich, J. Montez, and C. T. Nies. The Changing Nature of the Academic Deanship: ASHE-ERIC Higher Education Research Report. Jossey-Bass Publishers, San Francisco, CA, 2001.

\section{A Additional Data and Estimation Information}

This appendix describes the data sources we use and some details omitted in the main text.

\section{A.1 NLSY97}

For the National Longitudinal Sample of Youth 1997 (NLSY97), we restrict attention to the representative sample. We drop waves after 2012. We also drop any observations that report annual work hours in excess of 6000. Apart from that, every observation is included when possible (when possible meaning, e.g., that if zero earnings were reported, they are not included when measuring log earnings).

\section{A.2 IPEDS and Delta Cost Project}

For our sample selection in the Delta Cost Project (DCP), we require that the institution be present from 1987 to 2010, that they be a four-year, non-specialty institution according 
to the Carnegie Classification, that they be either public or private, non-profit, and that they have non-missing data on FTEs and net tuition. Additionally, we drop observations that had fewer than 100 FTE students or had net tuition per FTE outside of the 1-99th percentile range. To be included in the fixed effects regression, we additionally require that observations have cost per FTE inside of the 1-99th percentile range. Without trimming, the $R^{2}$ measures in the fixed effects regression are about $50 \%$ smaller (i.e., the within $R^{2}$ measure falls to around 0.1 and the overall measure falls to around .06).

The college budget constraint has custodial costs, an endowment, investment, and tuition. The corresponding data measures are as follows:

- Endowment: all non-tuition revenue, which is the sum of appropriated federal (nonPell) grants, appropriated state and local grants, and a auxiliary revenue (all per student).

- Investment: total education and general expenditures including sponsored research but excluding auxiliary enterprises.

- Tuition: net tuition and fees revenue.

- Custodial costs: a residual computed as the endowment plus tuition less investment.

As with Epple et al. (2006), we compute custodial costs as a residual. Our investment measure is perhaps too broad as it includes all education costs, rather than just minimal ones. However, it is unclear exactly what minimal expenditures on education should be.

A significant shortcoming in the DCP database is that financial variables that are reported as zero are converted to missing values (p. 14 del, 2011). Moreover, there are a large number of missing values for certain measures, including the appropriated state and local grants measure. For this measure in particular, one could imagine that many schools actually had zero appropriations.

For the estimation of the cost function, we of course require that a cost observation be non-missing. Since costs are computed as a residual, this also requires the endowment, investment, and tuition measures to also be non-missing. This results (after trimming) in 23,718 observations for costs (as well as endowment). Investment and net tuition have a total of 30,517 observations. The other variable we take from IPEDS, federal plus state government grants to students, has 23,047 observations (which may be a result of incorrectly missing values). 


\section{A.3 PSID}

For the Panel Study of Income Dynamics (PSID), we restrict the sample to heads of house-

holds (not necessarily male), aged 18 to 65, in the representative SRC (Survey Research Center) sample. For waves prior to 1991, we compute an estimate of the heads years of education using the education bucket variable (e.g., we treat "some college" as 14 years of education and "college" as 16 years) since actual years of education are not available.

\section{B Additional Transition Information}

This appendix provides estimates of how earnings have changed over the past few decades and provides historical information on the student loan programs.

\section{B.1 Model Units and Growth in Earnings}

Since we focus on steady states with only real variables, we need a way to convert dollar measures into our model. We do this by expressing all variables relative to average earnings in 2010. A natural concern is that average earnings have grown substantially over the sample period.

Indeed, earnings have grown substantially over the sample period. For instance, using the PSID, we compute four measures of real average family income: (1) head and wife labor income; (2) head and wife labor income plus transfers; (3) family income (which includes asset income); and (4) OECD-equivalized labor plus transfer income. Our preferred measure is (4), and the averages over time for all measures are displayed in figure 9. In figure 10, we also report the time series for average log values for our preferred measure.

While in every measure there has been this substantial earnings growth over time, other factors have been changing as well. Most importantly, college attainment has changed substantially over the last few decades. These changes could explain most or all of the changes in average earnings. To investigate this, we regressed our preferred income measure on age, age squared, and age cubed (results for age dummies are similar) and an education measure equal to $(\min (\max (e d u c, 12), 16)-12) / 4$ where educ is the heads years of education (the measure corresponds closely to our model). We restrict the sample to heads aged 18 to 65 . The regression results are reported in table 8 .

The results reveal that, after controlling for education attainment and age, almost all the growth in earnings is orthogonal to time. Because of this result, we restrict attention to steady states in the true sense of the word with average earnings growing over time only because of changes in educational attainment. It is worth noting that our implied college 


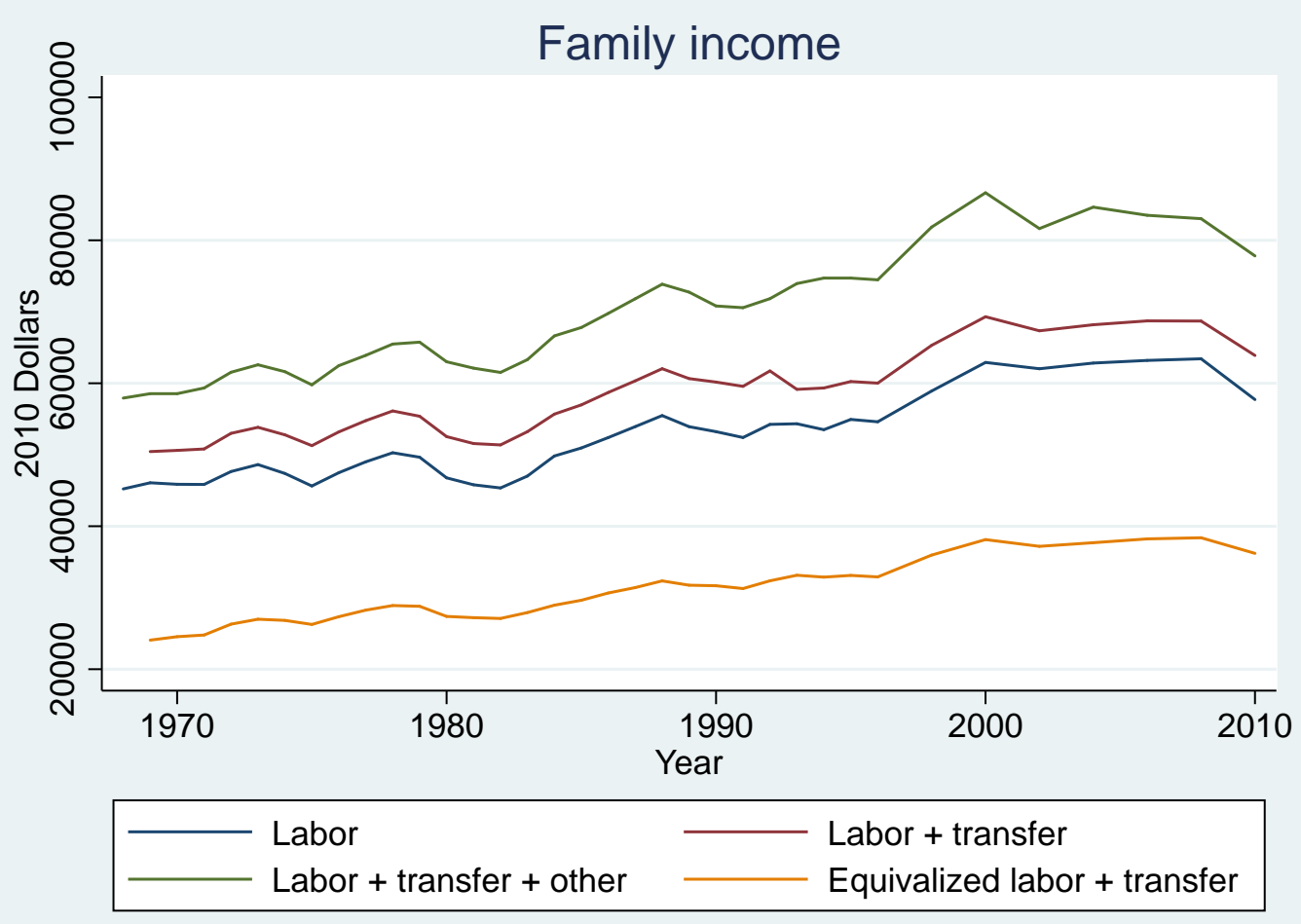

Figure 9: Average Income (2010 dollars)

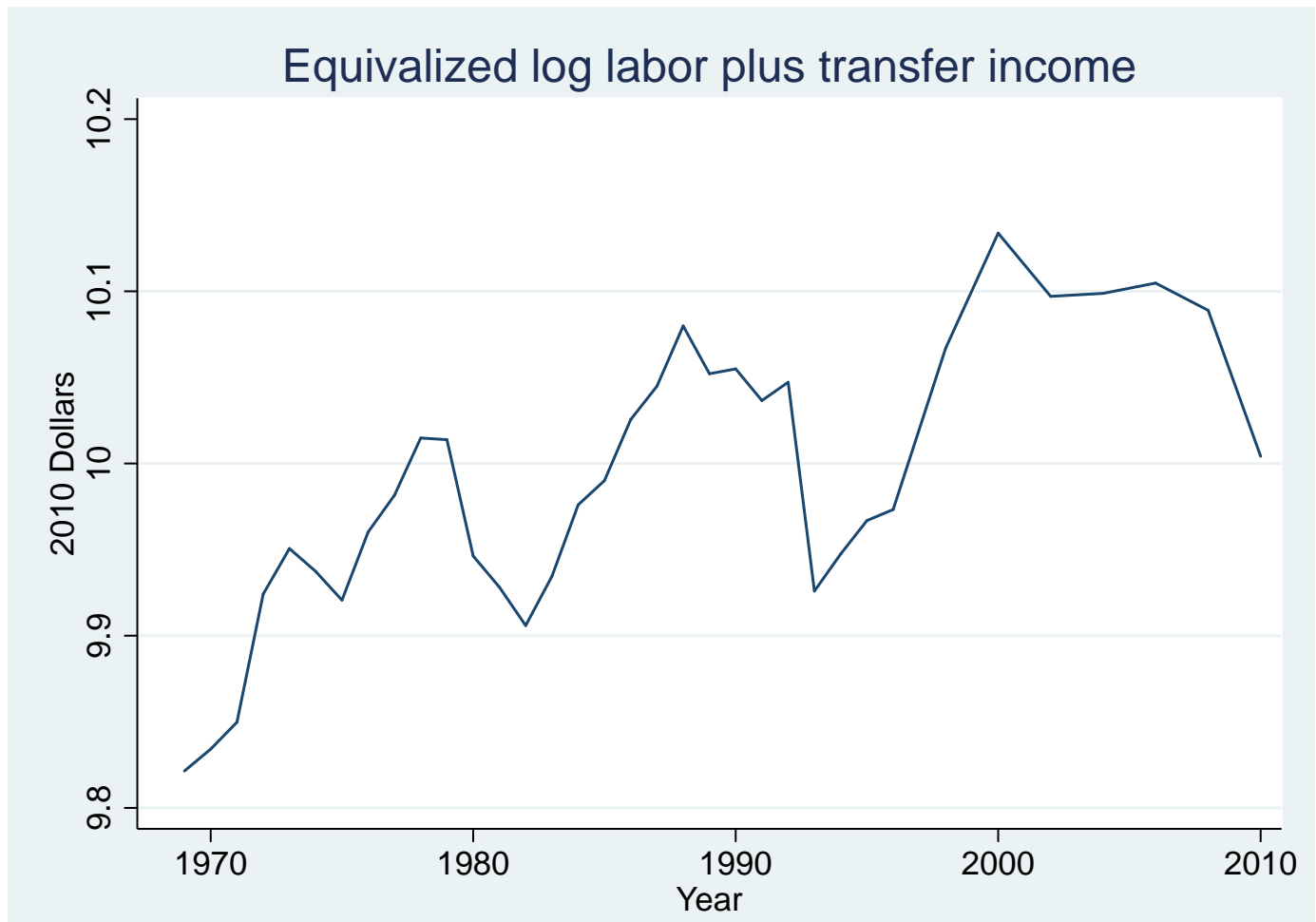

Figure 10: Average Log Equivalized Income (2010 Dollars) 


\begin{tabular}{lc}
\hline \hline & Equivalized income \\
\hline Year & 0.000359 \\
& $(0.000211)$ \\
Years of college education / 4 & 0.704 \\
& $(0.00578)$ \\
Age / 10 & 0.316 \\
& $(0.0652)$ \\
Age squared / 100 & 0.00546 \\
& $(0.0164)$ \\
Age cubed / 1000 & -0.00546 \\
Constant & $(0.00131)$ \\
& 8.254 \\
Observations & $(0.425)$ \\
$R^{2}$ & 116092 \\
\hline \hline
\end{tabular}

Standard errors in parentheses

Table 8: Estimates from Regression on Log Equivalized Labor Plus Transfer Income

earnings premia is 0.70, which is a bit higher than what Autor et al. (2008) would suggest. However, one should note that their earnings premia is restricted to full-time workers, while our measure has hours worked varying with characteristics.

Our model units are expressed as a fraction of average log equivalized income in 2010. Rounding slightly, this amount was $\$ 36,200$. In 1987 , this value was $\$ 31,400$, which is our target for averages earnings in 1987.

\section{B.2 Earnings Premium}

The estimates in Autor et al. (2008) only go until 2005. As stated in the main text, we fit a quadratic polynomial from 1987-2005 and use that to recover $\lambda_{t}$ values both in and out of sample. Figure 11 plots the actual and fitted college premium. Since the steep rise in the earnings premium began in 1981, we try to obtain something more akin to an initial steady state value by taking the seven-year average from 1981 to 1987 . We treat this average, 0.46, as the "1987" value.

\section{B.3 Student Loan Programs}

Government guaranteed loans have been available to students through two programs, the William D. Ford Federal Direct Loan (DL) and Federal Family Education Loan (FFEL) 


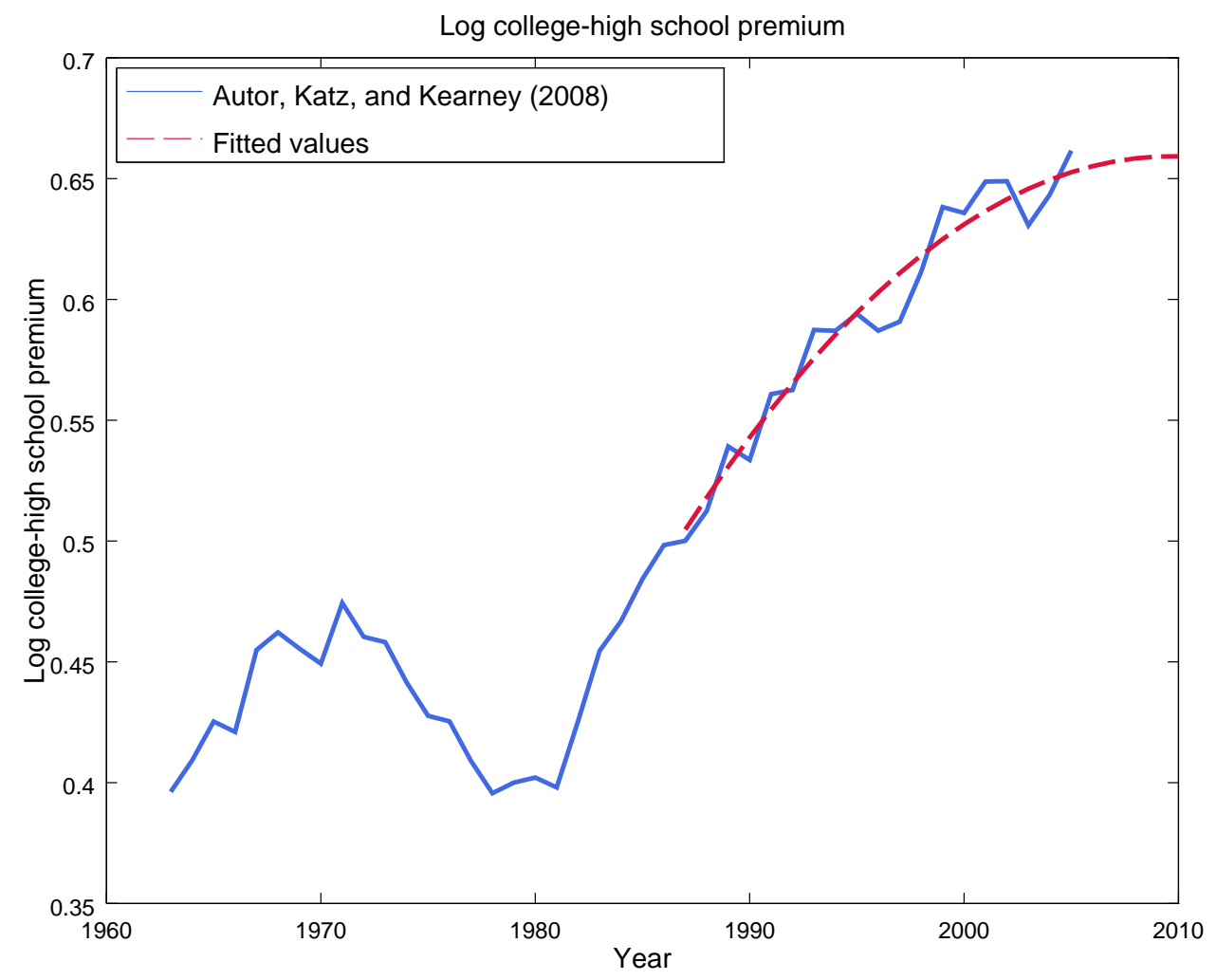

Figure 11: Log College Premium 
(Smole, 2012). The DL program has loan capital provided by the government while the FFEL has loan capital provided privately (Smole, 2012). In either case, losses due to default, death, or permanent disability have been paid for by the government (Smole, 2012).

Unsubsidized loans were introduced by the Higher Education Ammendments of 1992 Title IV, Part B, $\S 428 \mathrm{H} .{ }^{24}$ The loan limit was a combined subsidized and unsubsidized limit (i.e., students who were not eligible or only partly eligible for subsidized loans would be allowed to borrow the remainder via unsubsidized loans) $(\S 428 \mathrm{H}(\mathrm{d}))$.

Beginning in 1994, independent undergraduate students were able to borrow more than the combined subsidized/unsubsidized limit for dependent undergraduates (Smole, 2012). Then in 2008, the ability to borrow in unsubsidized loans was increased for dependent and independent undegraduates (Smole, 2012). Table 9 summarizes the historical loan limits, both the aggregate loan limits and the year-by-year limits.

To map these limits into our model, where we do not distinguish between dependent and independent students, we need to make an assumption. Choy (2002) shows that in 1999-2000, $37.6 \%(36.7 \%)$ of students at public (private) 4-year schools were financially independent. So, we create a combine dependent/independent limit by placing $37 \%$ of weight on the independent limit and $63 \%$ of weight on the dependent limit. The values are given in table 4 .

For our terminal steady state, we take the limits associated with 2010. For our initial steady state, we take the limits not associated with 1987, which were new that year, but rather with the limits in 1986 (which had been in place since 1981). The complete list of limits we use, in nominal terms, is given in table 10

Interest rates have also varied historically. From 1992 to 2006, the interest rates were given as a 91-day T-bill plus a spread while capped at a specified rate. In other years, interest rates have had a fixed rate between $3.4 \%$ and $10 \%$. Since 2008, there have also been separate interest rates for subsidized and unsubsidized loans. For completeness, these are reproduced from Smole (2012) in table 11.

In mapping these interest rates into the model, we first compute what the real student loan interest rate in period $\tau$ would be for a loan originated at time $t$, and call it $i_{t, \tau} \cdot{ }^{25} \mathrm{We}$ take $i_{t}$ to be the numerical average of $\left\{i_{t+j, t}\right\}_{j=-13}^{0}$. This average interest rate reflects that, in a standard 10-year repayment plan, cohorts from 13 years ago will be affected by the

\footnotetext{
${ }^{24}$ The content is available at https://www.govtrack.us/congress/bills/102/s1150/text. Retrieved: June 1, 2015.

${ }^{25}$ We measure this as the statutory rate minus the CPI inflation rate. For the statutory rate, we take the rate corresponding to November 1st in year $\tau$. For 1988 to 1992 , we use a rate of $9.6 \%=0.8 * 10 \%+0.2 * 8 \%$. Prior to 1988 , we use $8.5 \%$. For 2008 and beyond, we take the numerical average of the subsidized and unsubsidized rates.
} 


\begin{tabular}{|c|c|c|c|c|c|c|c|c|}
\hline & & & \multicolumn{6}{|c|}{ בAnnual limit } \\
\hline & \multicolumn{2}{|c|}{ Aggregate Limit } & \multicolumn{3}{|c|}{ Subsidized } & \multicolumn{3}{|c|}{ Combined } \\
\hline & Subsid. & Comb. & Yr. 1 & Yr. 2 & Yr. 3+ & Yr. 1 & Yr. 2 & Yr. 3+ \\
\hline \multicolumn{9}{|c|}{$10 / 1 / 81-12 / 31 / 86$} \\
\hline Dependent & 12,500 & - & 2,500 & 2,500 & 2,500 & - & - & - \\
\hline Independent & 12,500 & - & 2,500 & 2,500 & 2,500 & - & - & - \\
\hline \multicolumn{9}{|c|}{$1 / 1 / 87-9 / 30 / 92$} \\
\hline Dependent & 17,250 & - & 2,625 & 2,625 & 4,000 & - & - & - \\
\hline Independent & 17,250 & - & 2,625 & 2,625 & 4,000 & - & - & - \\
\hline \multicolumn{9}{|c|}{$10 / 1 / 92-6 / 30 / 93$} \\
\hline Dependent & 23,000 & - & 2,625 & 3,500 & 5,500 & - & - & - \\
\hline Independent & 23,000 & - & 2,625 & 3,500 & 5,500 & - & - & - \\
\hline \multicolumn{9}{|c|}{$7 / 1 / 93-6 / 30 / 94$} \\
\hline Dependent & 23,000 & 23,000 & 2,625 & 3,500 & 5,500 & 2,625 & 3,500 & 5,500 \\
\hline Independent & 23,000 & 23,000 & 2,625 & 3,500 & 5,500 & 2,625 & 3,500 & 5,500 \\
\hline \multicolumn{9}{|c|}{$7 / 1 / 94-6 / 30 / 07$} \\
\hline Dependent & 23,000 & 23,000 & 2,625 & 3,500 & 5,500 & 2,625 & 3,500 & 5,500 \\
\hline Independent & 23,000 & 46,000 & 2,625 & 3,500 & 5,500 & 6,625 & 7,500 & 10,500 \\
\hline \multicolumn{9}{|c|}{$7 / 1 / 07-6 / 30 / 08$} \\
\hline Dependent & 23,000 & 23,000 & 3,500 & 4,500 & 5,500 & 3,500 & 4,500 & 5,500 \\
\hline Independent & 23,000 & 46,000 & 3,500 & 4,500 & 5,500 & 7,500 & 8,500 & 10,500 \\
\hline \multicolumn{9}{|l|}{$7 / 1 / 08$} \\
\hline Dependent & 23,000 & 31,000 & 3,500 & 4,500 & 5,500 & 5,500 & 6,500 & 7,500 \\
\hline Independent & 23,000 & 57,500 & 3,500 & 4,500 & 5,500 & 9,500 & 10,500 & 12,500 \\
\hline
\end{tabular}

Note: A "-" means unsubsidized loans were not yet available; all values are in nominal terms. Source: Tables B-2 and B-3 in Smole (2012).

Table 9: Historical Loan Limit Information 


\begin{tabular}{ccccccccccccc}
\hline \hline year & $\bar{l}^{\text {sub }}$ & $\bar{l}^{\text {uns }}$ & $\bar{l}$ & $\bar{b}_{1}^{\text {sub }}$ & $\bar{b}_{2}^{\text {sub }}$ & $\bar{b}_{\geq 3}^{\text {sub }}$ & $\bar{b}_{1}^{\text {uns }}$ & $\bar{b}_{2}^{\text {uns }}$ & $\bar{b}_{\geq 3}^{\text {uns }}$ & $\bar{b}_{1}$ & $\bar{b}_{2}$ & $\bar{b}_{\geq 3}$ \\
\hline $1987^{*}$ & 12500 & 0 & 12500 & 2500 & 2500 & 2500 & 0 & 0 & 0 & 2500 & 2500 & 2500 \\
1988 & 17250 & 0 & 17250 & 2625 & 2625 & 4000 & 0 & 0 & 0 & 2625 & 2625 & 4000 \\
1989 & 17250 & 0 & 17250 & 2625 & 2625 & 4000 & 0 & 0 & 0 & 2625 & 2625 & 4000 \\
1990 & 17250 & 0 & 17250 & 2625 & 2625 & 4000 & 0 & 0 & 0 & 2625 & 2625 & 4000 \\
1991 & 17250 & 0 & 17250 & 2625 & 2625 & 4000 & 0 & 0 & 0 & 2625 & 2625 & 4000 \\
1992 & 23000 & 0 & 23000 & 2625 & 3500 & 5500 & 0 & 0 & 0 & 2625 & 3500 & 5500 \\
1993 & 23000 & 23000 & 23000 & 2625 & 3500 & 5500 & 2625 & 3500 & 5500 & 2625 & 3500 & 5500 \\
1994 & 23000 & 31510 & 31510 & 2625 & 3500 & 5500 & 4105 & 4980 & 7350 & 4105 & 4980 & 7350 \\
1995 & 23000 & 31510 & 31510 & 2625 & 3500 & 5500 & 4105 & 4980 & 7350 & 4105 & 4980 & 7350 \\
1996 & 23000 & 31510 & 31510 & 2625 & 3500 & 5500 & 4105 & 4980 & 7350 & 4105 & 4980 & 7350 \\
1997 & 23000 & 31510 & 31510 & 2625 & 3500 & 5500 & 4105 & 4980 & 7350 & 4105 & 4980 & 7350 \\
1998 & 23000 & 31510 & 31510 & 2625 & 3500 & 5500 & 4105 & 4980 & 7350 & 4105 & 4980 & 7350 \\
1999 & 23000 & 31510 & 31510 & 2625 & 3500 & 5500 & 4105 & 4980 & 7350 & 4105 & 4980 & 7350 \\
2000 & 23000 & 31510 & 31510 & 2625 & 3500 & 5500 & 4105 & 4980 & 7350 & 4105 & 4980 & 7350 \\
2001 & 23000 & 31510 & 31510 & 2625 & 3500 & 5500 & 4105 & 4980 & 7350 & 4105 & 4980 & 7350 \\
2002 & 23000 & 31510 & 31510 & 2625 & 3500 & 5500 & 4105 & 4980 & 7350 & 4105 & 4980 & 7350 \\
2003 & 23000 & 31510 & 31510 & 2625 & 3500 & 5500 & 4105 & 4980 & 7350 & 4105 & 4980 & 7350 \\
2004 & 23000 & 31510 & 31510 & 2625 & 3500 & 5500 & 4105 & 4980 & 7350 & 4105 & 4980 & 7350 \\
2005 & 23000 & 31510 & 31510 & 2625 & 3500 & 5500 & 4105 & 4980 & 7350 & 4105 & 4980 & 7350 \\
2006 & 23000 & 31510 & 31510 & 2625 & 3500 & 5500 & 4105 & 4980 & 7350 & 4105 & 4980 & 7350 \\
2007 & 23000 & 31510 & 31510 & 3500 & 4500 & 5500 & 4980 & 5980 & 7350 & 4980 & 5980 & 7350 \\
2008 & 23000 & 40805 & 40805 & 3500 & 4500 & 5500 & 6980 & 7980 & 9350 & 6980 & 7980 & 9350 \\
2009 & 23000 & 40805 & 40805 & 3500 & 4500 & 5500 & 6980 & 7980 & 9350 & 6980 & 7980 & 9350 \\
2010 & 23000 & 40805 & 40805 & 3500 & 4500 & 5500 & 6980 & 7980 & 9350 & 6980 & 7980 & 9350 \\
\hline \hline
\end{tabular}

*The "1987" limits correspond to the limits in place from 1981 to 1986.

Table 10: Borrowing Limit Transitions 


\begin{tabular}{|c|c|c|}
\hline & Subsidized & Unsubsidized \\
\hline \multicolumn{3}{|l|}{$1 / 1 / 81-6 / 30 / 88$} \\
\hline All & $9 \%$ or $8 \% *$ & - \\
\hline \multicolumn{3}{|l|}{$7 / 1 / 88-9 / 30 / 92$} \\
\hline First 48 months & $8 \%$ & $8 \%$ \\
\hline Remaining payment period & $10 \%$ & $10 \%$ \\
\hline \multicolumn{3}{|l|}{$10 / 1 / 92-6 / 30 / 94$} \\
\hline All & $\min \{$ T-bill $+3.1 \%, 9 \%\}$ & $\min \{$ T-bill $+3.1 \%, 9 \%\}$ \\
\hline \multicolumn{3}{|l|}{ 7/1/94-6/30/95 } \\
\hline All & $\min \{$ T-bill $+3.1 \%, 8.25 \%\}$ & $\min \{$ T-bill $+3.1 \%, 8.25 \%\}$ \\
\hline \multicolumn{3}{|l|}{$7 / 1 / 95-6 / 30 / 98$} \\
\hline In-school, grace, deferment & $\min \{$ T-bill $+2.5 \%, 8.25 \%\}$ & $\min \{$ T-bill $+2.5 \%, 8.25 \%\}$ \\
\hline Repayment periods & $\min \{$ T-bill $+3.1 \%, 8.25 \%\}$ & $\min \{$ T-bill $+3.1 \%, 8.25 \%\}$ \\
\hline \multicolumn{3}{|l|}{$7 / 1 / 98-6 / 30 / 06$} \\
\hline In-school, grace, deferment & $\min \{$ T-bill $+1.7 \%, 8.25 \%\}$ & $\min \{$ T-bill $+1.7 \%, 8.25 \%\}$ \\
\hline Repayment periods & $\min \{\mathrm{T}-\mathrm{bill}+2.3 \%, 8.25 \%\}$ & $\min \{$ T-bill $+2.3 \%, 8.25 \%\}$ \\
\hline \multicolumn{3}{|l|}{$7 / 1 / 06-6 / 30 / 08$} \\
\hline All & $6.8 \%$ & $6.8 \%$ \\
\hline \multicolumn{3}{|l|}{$7 / 1 / 08-6 / 30 / 09$} \\
\hline All & $6.0 \%$ & $6.8 \%$ \\
\hline \multicolumn{3}{|l|}{$7 / 1 / 09-6 / 30 / 10$} \\
\hline All & $5.6 \%$ & $6.8 \%$ \\
\hline \multicolumn{3}{|l|}{$7 / 1 / 10-6 / 30 / 11$} \\
\hline All & $4.5 \%$ & $6.8 \%$ \\
\hline
\end{tabular}

Note: A "-" means unsubsidized loans were not yet available. ${ }^{*} 9 \%$ if 12 -month average of; 91 -day T-bill $>9 \% ; 8 \%$ otherwise. Source: Table B-4 in Smole (2012).

Table 11: Historical Interest Rate Information 
current interest rate alongside the current cohort: Along the transition, payments in period $t$ on a loan of size $l$ with remaining duration $d$ are $p_{t}(l, d)=l \frac{i_{t}\left(1+i_{t}\right)^{d-1}}{\left(1+i_{t}\right)^{d}-1}$. Table 12 gives both the cohort specific interest rate $i_{\tau, \tau+j}$ at various lags along with the average across the 14 cohorts $i_{\tau}$.

\begin{tabular}{|c|c|c|c|c|c|c|c|c|c|c|c|c|c|c|c|}
\hline$\tau$ & 0 & 1 & 2 & 3 & 4 & 5 & $\begin{array}{l}i_{\tau,} \\
6\end{array}$ & $\begin{array}{l}j \\
7\end{array}$ & 8 & 9 & 10 & 11 & 12 & 13 & $i_{\tau}$ \\
\hline 1987 & 4.9 & 4.4 & 3.7 & 3.1 & 4.3 & 5.5 & 5.5 & 5.9 & 5.7 & 5.6 & 6.2 & 7.0 & 6.3 & 5.1 & 4.9 \\
\hline 1988 & 5.5 & 4.8 & 4.2 & 5.4 & 6.6 & 6.6 & 7.0 & 6.8 & 6.7 & 7.3 & 8.1 & 7.4 & 6.2 & 6.8 & 4.9 \\
\hline 1989 & 4.8 & 4.2 & 5.4 & 6.6 & 6.6 & 7.0 & 6.8 & 6.7 & 7.3 & 8.1 & 7.4 & 6.2 & 6.8 & 8.0 & 4.4 \\
\hline 1990 & 4.2 & 5.4 & 6.6 & 6.6 & 7.0 & 6.8 & 6.7 & 7.3 & 8.1 & 7.4 & 6.2 & 6.8 & 8.0 & 7.3 & 3.9 \\
\hline 1991 & 5.4 & 6.6 & 6.6 & 7.0 & 6.8 & 6.7 & 7.3 & 8.1 & 7.4 & 6.2 & 6.8 & 8.0 & 7.3 & 6.9 & 5.2 \\
\hline 1992 & 3.5 & 3.1 & 4.8 & 5.8 & 5.2 & 5.8 & 6.3 & 5.5 & 5.6 & 3.7 & 3.1 & 1.8 & 1.8 & 2.9 & 5.9 \\
\hline 1993 & 3.1 & 4.8 & 5.8 & 5.2 & 5.8 & 6.3 & 5.5 & 5.6 & 3.7 & 3.1 & 1.8 & 1.8 & 2.9 & 4.6 & 5.5 \\
\hline 1994 & 4.8 & 5.4 & 5.2 & 5.8 & 6.3 & 5.5 & 4.9 & 3.7 & 3.1 & 1.8 & 1.8 & 2.9 & 4.6 & 4.6 & 6.0 \\
\hline 1995 & 5.4 & 5.2 & 5.8 & 6.3 & 5.5 & 4.9 & 3.7 & 3.1 & 1.8 & 1.8 & 2.9 & 4.6 & 4.6 & 0.7 & 6.1 \\
\hline 1996 & 5.2 & 5.8 & 6.3 & 5.5 & 4.9 & 3.7 & 3.1 & 1.8 & 1.8 & 2.9 & 4.6 & 4.6 & 0.7 & 3.6 & 5.8 \\
\hline 1997 & 5.8 & 6.3 & 5.5 & 4.9 & 3.7 & 3.1 & 1.8 & 1.8 & 2.9 & 4.6 & 4.6 & 0.7 & 3.6 & 1.6 & 6.4 \\
\hline 1998 & 5.5 & 4.7 & 4.8 & 2.9 & 2.3 & 1.0 & 1.0 & 2.1 & 3.8 & 3.8 & -0.1 & 2.8 & 0.8 & -0.8 & 6.9 \\
\hline 1999 & 4.7 & 4.8 & 2.9 & 2.3 & 1.0 & 1.0 & 2.1 & 3.8 & 3.8 & -0.1 & 2.8 & 0.8 & -0.8 & 0.3 & 6.1 \\
\hline 2000 & 4.8 & 2.9 & 2.3 & 1.0 & 1.0 & 2.1 & 3.8 & 3.8 & -0.1 & 2.8 & 0.8 & -0.8 & 0.3 & 0.9 & 5.4 \\
\hline 2001 & 2.9 & 2.3 & 1.0 & 1.0 & 2.1 & 3.8 & 3.8 & -0.1 & 2.8 & 0.8 & -0.8 & 0.3 & 0.9 & 0.7 & 4.3 \\
\hline 2002 & 2.3 & 1.0 & 1.0 & 2.1 & 3.8 & 3.8 & -0.1 & 2.8 & 0.8 & -0.8 & 0.3 & 0.9 & 0.7 & 1.3 & 3.9 \\
\hline 2003 & 1.0 & 1.0 & 2.1 & 3.8 & 3.8 & -0.1 & 2.8 & 0.8 & -0.8 & 0.3 & 0.9 & 0.7 & 1.3 & 1.3 & 2.3 \\
\hline 2004 & 1.0 & 2.1 & 3.8 & 3.8 & -0.1 & 2.8 & 0.8 & -0.8 & 0.3 & 0.9 & 0.7 & 1.3 & 1.3 & 1.3 & 1.8 \\
\hline 2005 & 2.1 & 3.8 & 3.8 & -0.1 & 2.8 & 0.8 & -0.8 & 0.3 & 0.9 & 0.7 & 1.3 & 1.3 & 1.3 & 1.3 & 2.4 \\
\hline 2006 & 3.6 & 3.9 & 3.0 & 7.1 & 5.2 & 3.7 & 4.7 & 5.3 & 5.2 & 4.8 & 4.8 & 4.8 & 4.8 & 4.8 & 4.1 \\
\hline 2007 & 3.9 & 3.0 & 7.1 & 5.2 & 3.7 & 4.7 & 5.3 & 5.2 & 4.8 & 4.8 & 4.8 & 4.8 & 4.8 & 4.8 & 4.0 \\
\hline 2008 & 2.6 & 6.7 & 4.8 & 3.3 & 4.3 & 4.9 & 4.8 & 4.4 & 4.4 & 4.4 & 4.4 & 4.4 & 4.4 & 4.4 & 0.7 \\
\hline 2009 & 6.5 & 4.6 & 3.1 & 4.1 & 4.7 & 4.6 & 4.2 & 4.2 & 4.2 & 4.2 & 4.2 & 4.2 & 4.2 & 4.2 & 4.1 \\
\hline 2010 & 4.0 & 2.5 & 3.6 & 4.2 & 4.0 & 3.6 & 3.6 & 3.6 & 3.6 & 3.6 & 3.6 & 3.6 & 3.6 & 3.6 & 2.3 \\
\hline
\end{tabular}

Note: Values having $\tau+j \geq 2015$ are predicted assuming a nominal interest rate of $1 \%$ and inflation rate of $2 \%$.

Table 12: Historical Interest Rate Information

While these give interest rates for some of the years along the transition path, the actual transition from steady state to steady state may take several decades. In this case, it is unclear what $i_{\tau}$ should be. To illuminate this, figure 13 plots $i_{\tau}$ for $\tau=1987, \ldots, 2010$. While the average interest rate early on is around 5\%, it increases to a peak of around $7 \%$ before falling for a decade and finally hovering around 3\%. To obtain our initial steady state interest rate, we use the average of the rates from 1987 to 1991. Likewise, to obtain our final 
steady state rate, we use the average from 2006 to $2010 .{ }^{26}$ These average values are $4.7 \%$ and $3.0 \%$, and they are plotted alongside the historical interest rates for comparison.

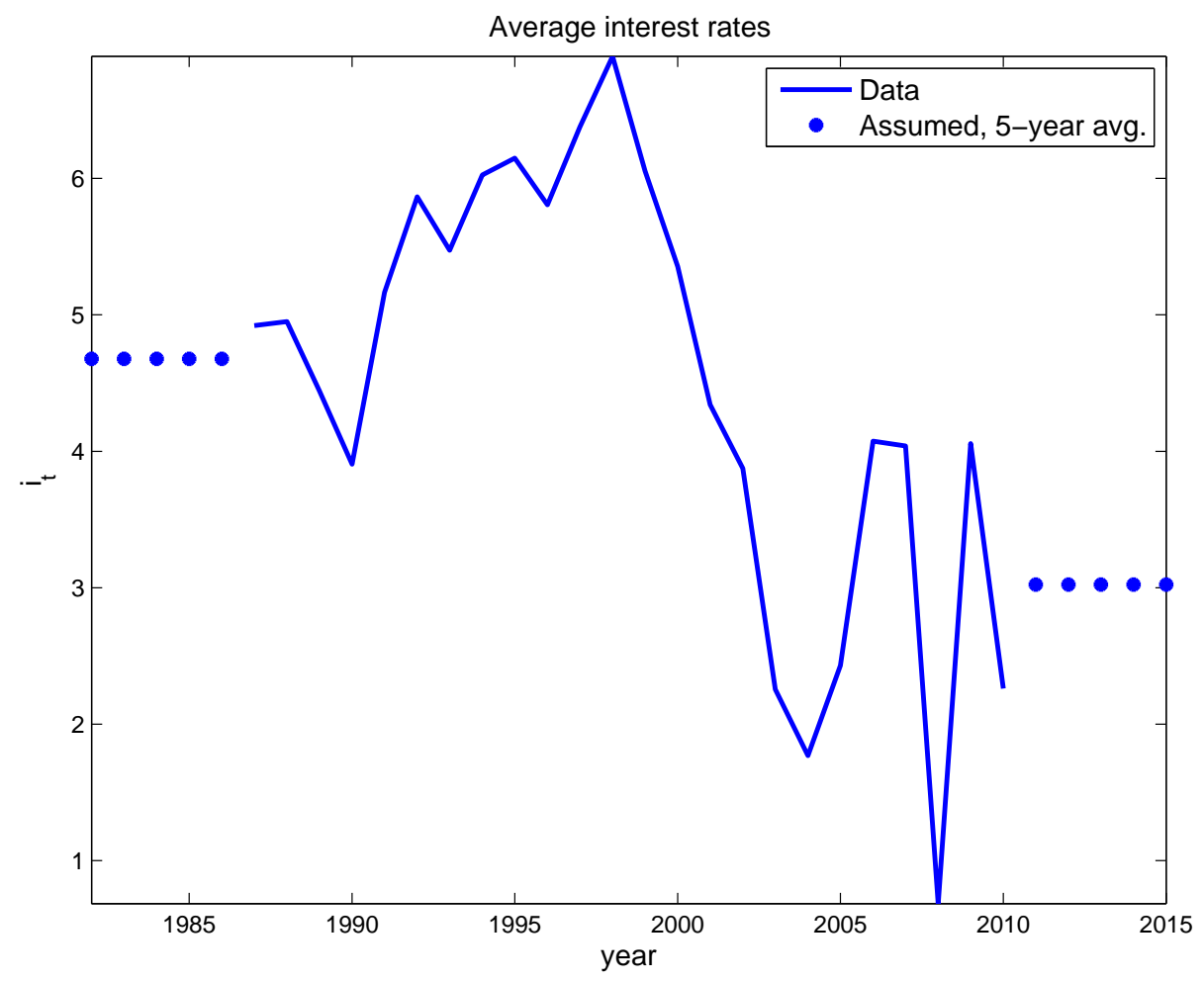

Table 13: Historical Interest Rates with Assumed Steady State Rates

\section{Computation}

This appendix describes some of the less trivial details of the computation. The worker and youth problems are mostly standard except that we use "binary monotonicity," a technique described in Gordon and Qiu (2015), to solve the worker problem very quickly. ${ }^{27}$ We focus the remaining discussion on the solution of the college problem and the transition.

\section{C.1 Solving the College Problem}

Computing the solution of the college problem is challenging. Since our value function for attending college takes into account many different features of the model, including borrowing

\footnotetext{
${ }^{26}$ Hence, in the computation, we replace the 1987 and 2010 values with those 5-year averages (so that our initial steady state corresponds to " 1987 " and terminal corresponds to "2010."

${ }^{27}$ In particular, the asset policy function is monotone in assets, so we can solve for the working problem in $O\left(n_{A} \log n_{A}\right)$ time (where $n_{A}$ is the number of asset grid points) else equal.
} 
limits, default, kinks, and a lack of feasibility of certain regions of the state space, it is not always smooth and is not well-defined in certain regions of the state space. Because of this, we found working with first order conditions (FOCs) untenable (which is the approach in Epple et al., 2006), at least for calibration/estimation where the model must be solved thousands of times for a wide range of parameter values.

Instead of working with FOCs, we directly maximize the college's quality function by choosing tuition. Specifically, we parameterize tuition as a bilinear function of the students ability and parental income. We construct a tensor product grid of ability and parental income. We then specify the value of tuition at those tensor-grid points, which implicitly defines a tuition function (via the bilinear interpolant) for the entire space. Given a particular guess on the tuition function, we must solve for enrollments, college investment, and college quality jointly. Specifically, we "guess" (i.e., solve a root-finding problem) on what the equilibrium college quality is, compute youth utility from attending (taking into the account the tuition they will pay and the utility they receive from college quality), compute enrollment probabilities, compute investment as a residual in the college budget constraint, and produce an implied college quality. We then check if the guess on quality and the implied quality are close enough. If not, we update the guess (in particular, we use bisection). ${ }^{28}$

The equilibrium tuition functions for 1987 and 2010 are displayed in figure 12. There is a great deal of variation in the tuition function. Some of the variation is immaterial: For the lowest ability youths, enrollment probabilities are virtually zero. Hence, any higher tuition level for them should generate essentially the same enrollment for this group (zero) and hence the same college quality. However, the tuition function also has substantial variation where youths do attend. In our discussion of figure 5, we described the main mechanism for why enrollment in 1987 is low for high ability, medium parental income youths. This discussion carries over almost directly to why tuition plummets for these students. In particular, colleges want the high ability students, but they have very little ability to pay. So tuition falls to accomodate some of them.

Given the variation in the tuition function, we decompose the process of finding the equilibrium tuition into a number of steps in an attempt to ensure we get close to the global maximum. To do this, we use three techniques: a multigrid, global search, and local search. We begin by specifying tuition on a very coarse grid for ability and parental income, two points in each dimension. We choose one thousand random points in the support of our tuition space. ${ }^{29}$ From each of these points, we perform a simplex search. We then take the

\footnotetext{
${ }^{28}$ Note that, unfortunately, we have no guarantee that the equilibrium is unique: If college quality is very high, willingness to pay is very high, which may justify the high college quality through higher enrollment of high-paying students.

${ }^{29}$ We make tuition a state variable and solve for the student value function on a grid (97 points linearly
} 

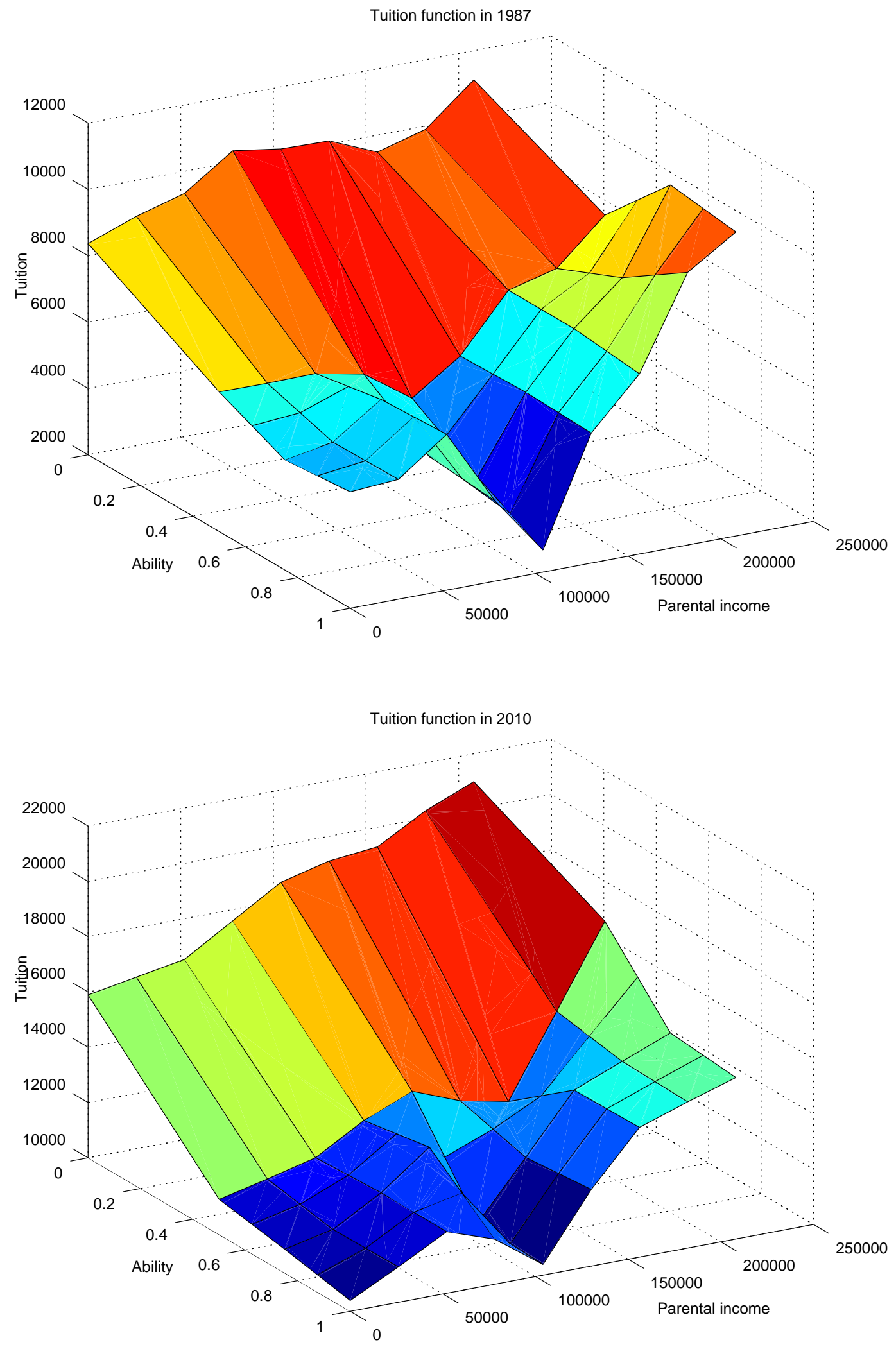

Figure 12: Tuition Functions in 1987 (Top) and 2010 (Bottom) 
best of these. This the truly global part of our search.

We then do a slightly less global approach. With the best guess on the tuition function from the global step, we take 31 random draws within plus or minus $\$ 1000$ and perform a simplex search from each (we also do a simplex search from the guess). Taking the best of these, we update our guess. We repeat this process three more times.

Our next step is the multigrid step. In particular, we refine the grid on ability and parental income. Our initial guess on the tuition function is the solution to the previous multigrid step. We then apply the global/local approach just described (32 draws four times). We repeat this multigrid process several times, eventually arriving at our desired grid that has six points in the ability dimension and nine points in the parental income dimension (equilibrium tuition has more curvature in the parental income dimension).

This approach typically yields large increases in quality for the first two multigrids and small increases (on the order of $2 \%$ or less) for the remaining five multigrids. Having small grids initially allows for a much more thorough exploration of the search space rather than simply starting with a six-by-nine grid. We tried a number of different approaches and found this one was both reliable and allowed substantial flexibility in the tuition function parameterization.

\section{C.2 Transition}

In the transition, the only unknown endogenous object that is needed to solve the household and college problem is the tax rate $\tau$. This is in part because we have taken care to formulate the college problem as static (and made certain other assumptions such as college being a once and for all choice made at time zero): The equilibrium $\theta, I, N$ can be determined at each point in time as long as the value function $Y_{1}\left(0, s_{Y} ; T\right)$, is known, and this value function does not depend on $\theta, I, N$, or $q .^{30}$

Our algorithm for computing the transition is as follows:

1. Fix $\underline{t}=1987-J+1$ and some terminal period $\bar{t} \gg 2010$. Guess on $\left\{\tau_{t}\right\}_{\underline{t}}^{\bar{t}}$.

2. For each cohort $t$ in $\underline{t}, \ldots, \bar{t}$, do the following:

(a) Use backward induction to compute the worker problem for all ages $j=1, \ldots, J$ (with $\tau$ and policies at age $j$ given by $t+j-1$ ). For cohorts that are surprised mid-life, the problem must be solved twice, once for before they were surprised

spaced between $\$ 0$ and $\$ 15000$ and three points at $\$ 20000, \$ 30000$, and $\$ 50000$, converted to model units). The support of the tuition space is $\$ 0$ to $\$ 50000$.

${ }^{30}$ Recall that college quality does affect utility, but it shows up at time zero as $Y_{1}+q$. 
(for all ages) and once for after they were surprised (for the age that they are surprised and on).

(b) Use backward induction to compute the student problem for all student ages $j=1, \ldots, J_{Y}$ taking tuition as given and with quality separate (don't compute $Y$ yet, just $\left.Y_{1}, \ldots, Y_{J_{Y}}\right)$. As in $2(\mathrm{a})$, the problem may need to be solved more than once.

(c) Compute the college problem solution, guessing $\theta, I, N$, computing $q$, the value $Y$, the tuition $T$, attendance based on EMC, and then updating the $\theta, I, N$ guesses until convergence is obtained.

3. For each cohort, simulate a panel. Use it to compute statistics, including the implied $\hat{\tau}_{t}$ needed to balance the government budget constraint.

4. Determine the supnorm $\max _{t \in\{\underline{t}, \ldots, \bar{t}\}}\left|\hat{\tau}_{t}-\tau_{t}\right|$. If it is less than .0005 , continue to the next stop. Otherwise, update the guess on $\tau_{t}$ according to $\tau_{t}:=(1-\rho) \tau_{t}+\rho \hat{\tau}_{t}$ where $\rho \in(0,1]$, and go to step $(2)$.

5. Check whether the specified transition length was long enough: If $\left|\tau_{t}-\tau^{*}\right|<.0005$, where $\tau^{*}$ is the terminal steady state value of $\tau$, then stop. Otherwise, go to (1) and increase $\bar{t}$.

We set $\bar{t}=2086$. In order to avoid storing policy functions for each cohort, we use Monte Carlo to compute statistics over the transition (this also requires solving for cohorts as far back as $1987-J+1) .{ }^{31}$ More precisely, we solve for a cohort's value and policy functions, simulate a panel for just that cohort, and compute statistics (such as means and standard deviations) on a rolling basis.

Students can be surprised by policy changes that can make their current stock of student loan debt infeasible. In particular, a tightening in the real borrowing limits with our $l^{\prime} \geq l$ assumption can result in infeasibility. To handle this, student borrowing terms and other financial aid variables are fixed for the duration of college.

\footnotetext{
${ }^{31}$ This technique allowed us to use MPI to much more easily parallelize the transition computation.
} 